\title{
The use of an oil-absorber-bioscrubber system during biodegradation of sequentially alternating loadings of 1,2-dichloroethane and fluorobenzene in
}

\section{a waste gas}

\author{
Michalis Koutinas $^{\mathrm{a}}$, Inês I.R. Baptista ${ }^{\mathrm{a}}$, Andrea Meniconi ${ }^{\mathrm{b}}$, Ludmila G. Peeva ${ }^{\mathrm{a}}$, \\ Athanasios Mantalaris $^{\mathrm{a}}$, Paula M.L. Castro ${ }^{\mathrm{c}}$, Andrew G. Livingston ${ }^{\mathrm{a}, *}$ \\ ${ }^{a}$ Department of Chemical Engineering and Chemical Technology, Imperial College London, SW7 2AZ London, UK \\ ${ }^{\mathrm{b}}$ Dipartimento di Ingegneria Chimica Mineraria e delle Tecnologie Ambientali, Università degli Studi di Bologna, Viale Risorgimento, 2-40136 Bologna, Italy \\ ${ }^{\mathrm{c}}$ Escola Superior de Biotecnologia, Universidade Católica Portuguesa, Rua Dr. António Bernardino de Almeida, 4200-072 Porto, Portugal
}

Keywords: 1,2-Dichloroethane; Fluorobenzene; Absorption; Bioreactors; Environment; Molecular biology

\begin{abstract}
This work seeks to improve the robustness of vapour phase bioscrubbing by applying an absorber prior to a bioscrubber during the dynamic treatment of sequentially alternating loads of inhibitory pollutants. Rhizobiales sp. strain F11 and Xanthobacter autotrophicus sp. GJ10, exhibiting specific degradation capabilities for fluorobenzene (FB) and 1,2-dichloroethane (DCE), respectively, were used as a compound-strain model system. The stability of a combined oil-absorber-bioscrubber (OAB) was compared to the stability of a bioscrubber only (BO) system, during sequentially alternating periods (duration 3-6d) of FB and DCE in the gas feed. The OAB achieved $>66 \%$ degradation of FB, while in the BO system the FB removal efficiency dropped to $0 \%$ upon restoring FB feed after a $3 \mathrm{~d}$ FB starvation period. Following $6 \mathrm{~d}$ of FB starvation the $\mathrm{BO}$ failed to recover within $10 \mathrm{~d}$, while the $\mathrm{OAB}$ required only $2 \mathrm{~d}$ to recover. In contrast, during the DCE treatment periods the $\mathrm{OAB}$ system did not show any advantage over the $\mathrm{BO}$ system. Further investigation showed that the $\mathrm{F}^{-}$(a main metabolic product from $\mathrm{FB}$ degradation) has a strong inhibitory effect on strain GJ10 even at concentrations below $50 \mathrm{mg} \mathrm{L}^{-1}$. In the OAB system the inhibitory effect persisted for longer periods due to the absorber, which continued to supply FB to the system, and caused deterioration in the DCE removal efficiency. The inhibition of the microbial culture was confirmed by fluorescence in situ hybridisation (FISH), which showed that the activity of cells was reduced when only FB was fed. The results of this study have shown that in the presence of an inhibitory metabolic product the OAB system may not effectively improve the biological treatment of waste gas during sequential alternations in the feed of inhibitory pollutants.
\end{abstract}

\section{Introduction}

A critical characteristic of industrial waste streams is the random variations in the pollutants concentration profiles (Koutinas et al., 2006, 2007). Past studies have extensively described the responses of biological systems to changes in pollutant concentration. Furthermore, various bioreactor designs and control strategies have been proposed to enhance

\footnotetext{
* Corresponding author. Tel.: +44 2075945582; fax: +44 2075945604.

E-mail address: a.livingston@ic.ac.uk (A.G. Livingston).
}

bioreactor stability, in most cases using absorption or adsorption materials contained within the bioreactor, or as a separate unit prior to the bioreactor. Granular activated carbon and solid polymers have been applied for the control of fluctuating pollutant loads (Weber and Hartmans, 1995; Abumaizar et al., 1998; Amsden et al., 2003; Daugulis et al., 2003). However, organic solvents or oils are expected to have higher capacities for most organic substrates (Daugulis, 1997; Daugulis et al., 2003). Recently, cost effective and environmentally friendly organic absorbents were exploited for the control of inhibitory concentrations of pollutants and starvation periods in bioscrubber systems, producing successful results (Oliveira and Livingston, 2003; Nielsen et al., 2005; Koutinas et al., 2006, 2007). 
However, there has been limited work performed to study responses during periodic switches in carbon source (Ferreira Jorge and Livingston, 2000a). The application of cost effective and environmentally friendly organic absorbents for the control of biological treatment of such waste streams would be an interesting approach. The scenario of sequential changes in the waste stream chemical composition is referred to in this work as 'sequentially alternating pollutants' (SAP), and describes cases in which the chemical composition is alternating sequentially from one set of compounds to another over cycle periods of days or weeks.

The first study introducing a SAP feeding scenario to bioreactors was performed by Goodall et al. (1998). Two immobilised cell airlift reactors were compared, during the biodegradation of an alternating sequence of meta- and para-nitrobenzoic acid by two specific microbial strains. The comparison showed that when the strains were co-immobilised, due to microbial interactions the system could respond faster to the re-introduction of each isomer, than when each strain was immobilised on different beads. In a separate study Goodall and Peretti (1998) developed a mathematical model to describe the co-immobilised configuration, predicting successfully the metabolic behaviour of the co-immobilised culture.

Ferreira Jorge and Livingston (2000a) investigated the biodegradation (by two specific microbial strains) of an alternating feed of monochlorobenzene (MCB) and DCE in a continuous stirred tank bioreactor (CSTB). Although the system required re-acclimation for the first few hours after DCE was re-introduced, re-acclimation was not observed when the feed was switched to MCB. The authors concluded that the strain degrading MCB was maintained in an active state in the CSTB when only DCE was fed, due to microbial interactions between the two species. To prevent undesirable DCE accumulation, a continuous flow of a 'maintenance feed' was introduced which enhanced the CSTB performance. However, it was not considered a feasible solution due to the excessive amounts of DCE required. Ferreira Jorge and Livingston (2000b) also investigated the performance of an extractive membrane bioreactor (EMB) challenged with SAP loads, using the same compoundstrain model system. The physical retention of the biomass due to the biofilm improved the performance of the system, and both strains were retained active in the EMB. However, recent studies have shown that the response of bioreactors to SAP conditions is also dependent on the physicochemical properties of the pollutants fed (Kim et al., 2005; Cai et al., 2006).

The above studies indicate that the greater the variability of pollutants in the waste stream, the greater the constraints on bioreactors treating such waste streams. They also suggest two strategies to overcome loss of degradation during SAP conditions: (i) the physical retention of biomass in the system via immobilisation, which can reduce the response time of the system after the switch in the substrate feed, and (ii) the maintenance of the microbial culture activity with the addition of an external carbon source as a maintenance feed, which has been proven successful even during the pilot scale operation of biological plants (Bastos et al., 2003).
The smoothing effect of an absorber, as proven when dealing with variations in the process inlet concentration (Koutinas et al., 2006, 2007), might be a successful alternative in meeting the challenges offered by SAP conditions during treatment. The present work investigates the potential of an oil absorber placed upstream of a bioscrubber to stabilise the biological treatment of waste gas during sequentially alternating loads of FB and DCE. The stability of the OAB and the BO systems was compared under SAP treatment conditions and a mathematical model was used to describe the operation of the absorber. In parallel, the microbial culture dynamics were monitored using FISH.

\section{Materials and methods \\ Cultivation of microorganisms}

Subcultures of Xanthobacter autotrophicus GJ10 and Rhizobiales sp. strain F11 were used for bioscrubber inoculation, and were grown under mineral medium and conditions described by Koutinas et al. (2006).

\section{Experimental set-up}

The experimental set-up used is presented in Fig. 1. The total flow rate of air influent to the system was $0.3 \mathrm{~L} \mathrm{~min}^{-1}$ and consisted of three different gas streams (G1-3), giving a volumetric gas flow rate per bioscrubber volume of $0.2 \mathrm{~min}^{-1}$. Streams G1 and G2 were enriched with FB and DCE, respectively, by passing through two saturation vessels containing pure compounds, while stream G3 comprised air. Gas direction I was followed when the absorber was not used and the waste gas was introduced directly to the bioscrubber. The bioscrubber (SGI '30/SET002', SGE, France) was operated with $1.5 \mathrm{~L}$ working volume and at a dilution rate of $0.023 \mathrm{~h}^{-1}$, controlled by a Watson Marlow 502S (Watson-Marlow Bredel Products, UK) peristaltic pump. The dissolved oxygen concentration was monitored via an Ingold oxygen probe (Mettler Toledo Ltd, UK), pH was controlled at $7 \pm 0.05$ with the addition of $2 \mathrm{M} \mathrm{H}_{2} \mathrm{SO}_{4}$ or $2 \mathrm{M} \mathrm{NaOH}$ and temperature was maintained constant at $30^{\circ} \mathrm{C}$. A stainless steel sparger was used to supply the inlet gas stream to the bioscrubber and two impellers rotating at $1000 \mathrm{rpm}$ were used for gas dispersion. The bioscrubber was operated under non-sterile conditions during the experiments. The absorber was a glass column $(50 \mathrm{~cm}$ height, $5 \mathrm{~cm}$ i.d.) divided into a packed section with a $27 \mathrm{~cm}$ high bed of pall rings, and an oil reservoir. The gas stream inlet was placed between the two sections, at $10 \mathrm{~cm}$ column height and the two streams (gas and oil) flowed in counter-current mode. A $0.52 \mathrm{~L}$ of sunflower oil (Pure Sunflower Oil, Tesco Stores Ltd, UK) was used. The oil was recirculated at a flow rate of $1 \mathrm{~L} \mathrm{~min}^{-1}$ via a gear pump (130-000-110 model, Cole-Parmer Instrument Company Ltd, London, UK) through the column, in order to mix the oil with the gas phase in the packed section. A temperature controller was employed to maintain the column temperature constant at $27^{\circ} \mathrm{C}$, utilising a thermocouple and a heating coil. 


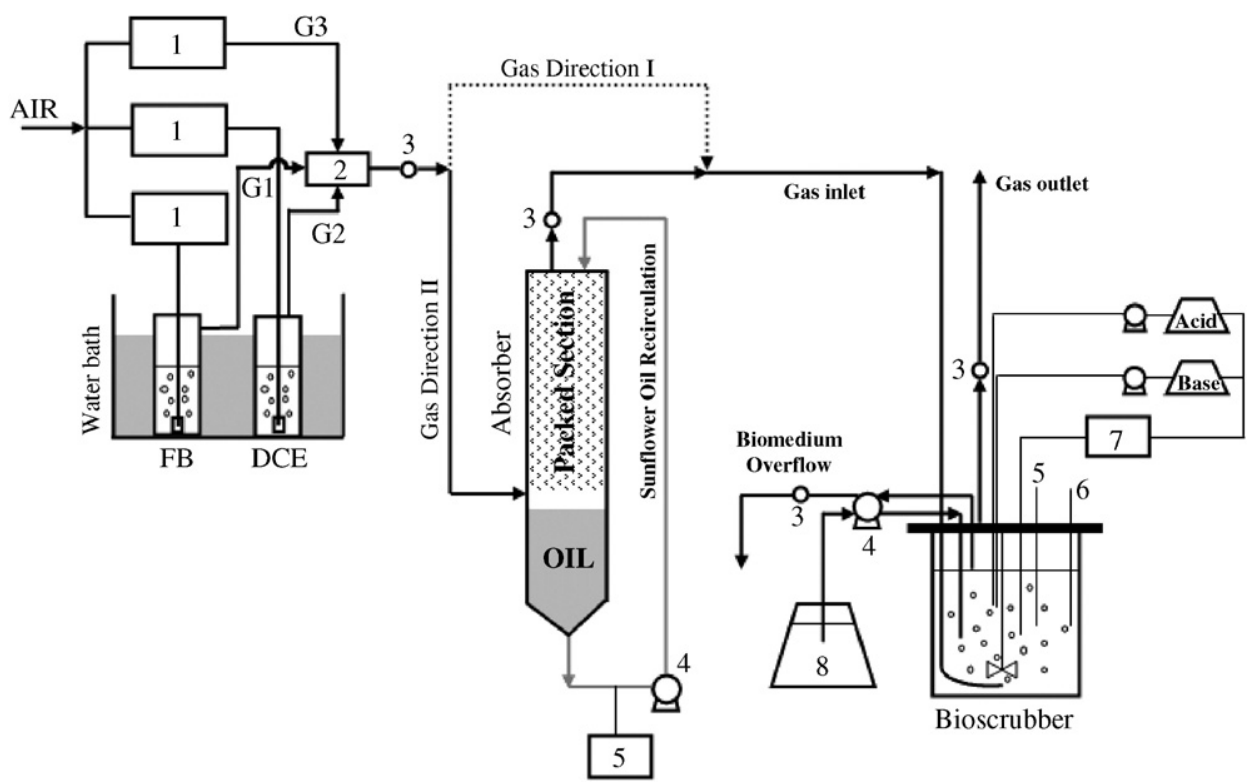

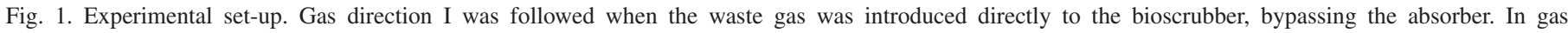

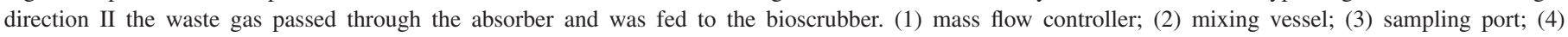
pump; (5) temperature controller; (6) dissolved oxygen meter; (7) pH controller; (8) mineral medium; G1, G2, G3: gas streams.

\section{Chemicals}

All chemicals used were obtained from Merck (UK) and were of ANALAR grade. DCE and FB were obtained from Sigma (UK) and were $99 \%$ pure.

\section{Analysis}

Carbon dioxide concentration in the gaseous samples and GJ10 biomass dry cell concentration in the shake flasks tests were determined as previously described (Koutinas et al., 2006). Furthermore, anions and cations in the biomedium were determined using ion chromatography as described by Koutinas et al. (2005).

An Agilent 6850 Series II Gas Chromatograph (GC) with a flame ionisation detector and a 'J\&W Scientific' (Agilent Technologies UK Limited, UK) column with HP-1 stationary phase $(30 \mathrm{~m} \times 0.32 \mathrm{~mm} \times 0.25 \mu \mathrm{m})$ was employed for the determination of the DCE and FB concentrations in the gaseous and aqueous samples. The flow rate of the mobile phase $(\mathrm{He})$ was set to $1 \mathrm{~mL} \mathrm{~min}^{-1}$ in order to achieve satisfactory separation between DCE and FB peaks. For gaseous samples, $25 \mu \mathrm{L}$ were injected into the $\mathrm{GC}$ and the temperature program run at a constant temperature of $30^{\circ} \mathrm{C}$ for $8 \mathrm{~min}$. Biomedium samples were centrifuged for $10 \mathrm{~min}$ at $13000 \mathrm{rpm}$ and the supernatant solution was filtered through $0.2 \mu \mathrm{m}$ filters to remove any remaining solids. Eight $\mathrm{mL}$ of the centrifuged sample was vortexed for $1 \mathrm{~min}$ with $2.5 \mathrm{~mL}$ of $n$-decane and finally $1 \mu \mathrm{L}$ of the $n$-decane solution was injected into the GC. For analysis of these biomedium samples, the GC column temperature was kept constant for $8 \mathrm{~min}$ at $30^{\circ} \mathrm{C}$ and then increased by $40^{\circ} \mathrm{C} \mathrm{min}{ }^{-1}$ to $260^{\circ} \mathrm{C}$. The coefficients of variation for six samples were $2.3 \%$ for DCE and $3.7 \%$ for $\mathrm{FB}$ at concentration levels of $7.6 \mathrm{mg}_{\mathrm{DCE}} \mathrm{L}^{-1}$ and $1.1 \mathrm{mg}_{\mathrm{FB}} \mathrm{L}^{-1}$.

\section{Partition coeficient}

The temperature dependence of the FB partition coefficient for sunflower oil was determined. Two $\mathrm{mL}$ Teflon coated closed vials were filled with $1 \mathrm{~mL}$ each of sunflower oil. A known mass of FB was injected into the vials, vortexed for $1 \mathrm{~min}$ and the vials were kept at different temperatures overnight (after which FB equilibrium between the oil and gas phases was assumed to occur), ranging between 20 and $36^{\circ} \mathrm{C}$. The concentration of $\mathrm{FB}$ in the oil phase was between 10 and $50 \mathrm{~g} \mathrm{~L}^{-1}$. The headspace FB concentration $C_{G \text {, FB }}$ was measured by GC analysis and the partition coefficient for each temperature was calculated assuming Henry's Law (Eq. (1)). The partition coefficient for DCE was previously estimated using the method described above (Koutinas et al., 2006):

$P_{\text {sun,oil }}^{\mathrm{FB}}=\frac{C_{\text {sun,oil }}^{\mathrm{FB}}}{C_{G, \mathrm{FB}}}$.

\section{Inhibitory effect of F - on GJ10}

The effect of increasing $\mathrm{F}^{-}$concentration on the growth of GJ10 on DCE was also explored. Six shake flasks were prepared containing $100 \mathrm{~mL}$ of mineral medium and $400 \mathrm{~mL}$ headspace. Potassium fluoride was added to each flask, resulting in $\mathrm{F}^{-}$ concentrations ranging between 0 and $200 \mathrm{mg} \mathrm{L}^{-1}$. The flasks were autoclaved prior to inoculation in order to ensure that the GJ10 culture would grow under sterile conditions. All the flasks were inoculated with $5 \mathrm{~mL}$ each from the same GJ10 
Table 1

Growth of F11 and GJ10 strains on DCE and FB

\begin{tabular}{llll}
\hline & Substrate & Strain & Growth $^{\mathrm{a}}$ \\
\hline Flask 1 & $2 \mathrm{mM} \mathrm{FB}$ & GJ10 & - \\
Flask 2 & $2 \mathrm{mM} \mathrm{DCE}$ & F11 & - \\
Flask 3 & $2 \mathrm{mM} \mathrm{FB}$ and 2 mM DCE & GJ10 & + \\
Flask 4 & $2 \mathrm{mM} \mathrm{FB}$ and 2 mM DCE & F11 & + \\
\hline
\end{tabular}

abbreviations: -, no growth after $4 \mathrm{~d}$; +, clearly visible growth in liquid culture after $4 \mathrm{~d}$.

inocula, grown on DCE and taken from the exponential phase. Following the inoculation of GJ10, DCE was added to each flask at a concentration of $2 \mathrm{mM}\left(198 \mathrm{mg} \mathrm{L}^{-1}\right)$. Additionally, a control flask was prepared as described above but without the addition of potassium fluoride and GJ10 inoculum, in order to measure the evaporation of DCE in the headspace. All the shake flasks were placed on a rotary shaker at $30^{\circ} \mathrm{C}$. After $20 \mathrm{~h}$, biomass, $\mathrm{Cl}^{-}$release and DCE concentration were measured in the biomedium of the flasks.

\section{Degradation of DCE and FB by F11 and GJ10}

Prior to the operation of the $\mathrm{BO}$ and $\mathrm{OAB}$ systems, the degradation capabilities of F11 and GJ10 for the two substrates were tested under different conditions as shown in Table 1. Five hundred $\mathrm{mL}$ flasks were used for the tests, containing $100 \mathrm{~mL}$ mineral medium and $400 \mathrm{~mL}$ headspace. The inoculation of each strain was performed under sterile conditions.

\section{Bacterial population analysis}

The GJ10 specific oligonucleotide probe [5'-TGT GTG CAG GTC CAT TGC TG-3'] derived from Emanuelsson et al. (2005) was used for the identification of GJ10 cells within the microbial community. It was labelled at the $5^{\prime}$ end with $\mathrm{Cy} 3$ fluorochrome (Thermo Electron GmbH, Germany). For the identification of F11 cells an oligonucleotide probe [5'-TTT GGA GAT TTG CTA AGG G-3'], labelled at the $5^{\prime}$ end with Cy3 fluorochrome was used. The specific probe for F11 was designed within our research group using Primrose computer software as described by Ashelford et al. (2002). Both oligonucleotide probes target the $16 \mathrm{~S}$ rRNA. General stains such as $4^{\prime} 6^{\prime}$-diamino-2-phenylindole (DAPI) and propidium iodide (PI) were used for determining the total number of cells and dead cells in the microbial population, respectively (Williams et al., 1998). EUB338I oligonucleotide probe was used as an indicator of ribosomal activity in cells (Poulsen et al., 1993).

For the FISH analysis, cells harvested from the bioreactor in $1 \mathrm{~mL}$ biomedium samples (diluted to OD $\sim 0.2$ ) were centrifuged at $13000 \mathrm{rpm}$ for $10 \mathrm{~min}$ and washed twice in $1 \mathrm{~mL}$ PBS buffer (1040 mg L ${ }^{-1} \mathrm{Na}_{2} \mathrm{HPO}_{4}, 332 \mathrm{mg} \mathrm{L}^{-1} \mathrm{NaH}_{2} \mathrm{PO}_{4}$ and $754 \mathrm{mg} \mathrm{L}^{-1} \mathrm{NaCl}$ ) and $10 \mu \mathrm{L}$ of $0.1 \%$ (w/w) Igepal solution. The cells were then fixed for $1 \mathrm{~h}$ at $4{ }^{\circ} \mathrm{C}$ in $4 \%$ paraformaldehyde and stored in a 1:1 mixture of ethanol and PBS. The rest of the procedure was performed as described by Koutinas et al. (2006). However, the two specific probes utilised the same fluorochrome. Therefore, each of the specific probes was added at separate wells in order to visualise one of the two strains under the microscope each time.

\section{Results and discussion}

\section{Absorber design}

As shown before, environmentally friendly and cost effective absorbents such as vegetable oils exhibit a great potential for absorption of halogenated organic compounds (Johnson et al., 2000; Koutinas et al., 2006, 2007). Thus, sunflower oil was chosen for absorption of DCE and FB in the absorber and the absorption capacity of sunflower oil for DCE was previously estimated by Koutinas et al. (2006). In order to estimate the absorption capacity of sunflower oil for FB, the sunflower oil partition coefficient for FB was determined prior to the experiments. The temperature dependence of the sunflower oil partition coefficient for FB was determined experimentally for temperatures between 20 and $36^{\circ} \mathrm{C}$. For this temperature range, the temperature dependence of the partition coefficient is linear and is expressed as

$P_{\text {sun }, \text { oil }}^{\mathrm{FB}}=-19.7 T+1622.3$.

The temperature dependence of the oil partition coefficient for FB and DCE suggests the potential for future work varying the temperature of the oil to control the absorption or desorption of the pollutants. Therefore, during periods of high substrate load the temperature of the oil might be decreased to absorb higher amounts of pollutants, while during starvation periods it can be increased to desorb the pollutants and maintain the bacterial culture in the bioreactor active.

\section{Mathematical modeling}

Following the estimation of the sunflower oil partition coefficient for FB, a mathematical model of the absorber described by Koutinas et al. (2007) was applied to the present system. In order to describe the performance of the absorber during the SAP experiments, the absorption of FB is described using Eqs. (2)-(4) and the absorption of DCE is described by Eqs. (5)-(7) based on the following assumptions:

- The partition coefficients for FB and DCE between sunflower oil and air are temperature dependent and are described by Eqs. (2) and (7), respectively. Eq. (7) was estimated in previous work (Koutinas et al., 2006).

- The liquid and gas phases in the absorber are perfectly mixed.

- No volume change occurs upon absorption.

The absorption and desorption profiles of FB and DCE in the absorber can be described by the following equations, derived from the mass balance of the two compounds in the gas stream (Eqs. (3), (5)) and their accumulation in sunflower 
oil (Eqs. (4), (6)).

$G\left(C_{\mathrm{a}, \text { in }}^{\mathrm{FB}}-C_{\mathrm{a}, \text { out }}^{\mathrm{FB}}\right)=\left(K_{L} a\right)_{\mathrm{oil}}^{\mathrm{FB}} V_{\mathrm{oil}}\left(C_{\mathrm{a}, \text { out }}^{\mathrm{FB}} P_{\text {sun,oil }}^{\mathrm{FB}}-C_{\text {sun,oil }}^{\mathrm{FB}}\right)$,

$\left(K_{L} a\right)_{\mathrm{oil}}^{\mathrm{FB}} V_{\mathrm{oil}}\left(C_{\mathrm{a}, \text { out }}^{\mathrm{FB}} P_{\text {sun,oil }}^{\mathrm{FB}}-C_{\text {sun,oil }}^{\mathrm{FB}}\right)=V_{\mathrm{oil}} \frac{\mathrm{d} C_{\mathrm{sun}, \text { oil }}^{\mathrm{FB}}}{\mathrm{d} t}$,

$G\left(C_{\mathrm{a}, \text { in }}^{\mathrm{DCE}}-C_{\mathrm{a}, \text { out }}^{\mathrm{DCE}}\right)=\left(K_{L} a\right)_{\mathrm{oil}}^{\mathrm{DCE}} V_{\mathrm{oil}}\left(C_{\mathrm{a} \text {,out }}^{\mathrm{DCE}} P_{\text {sun,oil }}^{\mathrm{DCE}}-C_{\text {sun,oil }}^{\mathrm{DCE}}\right)$,

$\left(K_{L} a\right)_{\text {oil }}^{\mathrm{DCE}} V_{\mathrm{oil}}\left(C_{\mathrm{a}, \text { out }}^{\mathrm{DCE}} P_{\text {sun,oil }}^{\mathrm{DCE}}-C_{\text {sun,oil }}^{\mathrm{DCE}}\right)=V_{\mathrm{oil}} \frac{\mathrm{d} C_{\text {sun,oil }}^{\mathrm{DCE}}}{\mathrm{d} t}$,

$P_{\text {sun,oil }}^{\mathrm{DCE}}=-12.1 T+1049.6$.

The set of Eqs. (2)-(7) was solved using gPROMS (Process Systems Enterprise, UK). The gas flow rate $G$ was constant during the experiment and had a value of $5 \times 10^{-3} \mathrm{~L} \mathrm{~s}^{-1}$ $\left(0.3 \mathrm{~L} \mathrm{~min}^{-1}\right)$. The temperature of the absorber was also constant at $27^{\circ} \mathrm{C}$. The input values of the absorber gas inlet concentrations $\left(C_{\mathrm{a}, \text { in }}^{\mathrm{DCE}}, C_{\mathrm{a}, \text { in }}^{\mathrm{FB}}\right)$ were estimated according to the measured experimental values while the sunflower oil volume $\left(V_{\text {oil }}\right)$ used was $0.52 \mathrm{~L}$. The volumetric liquid phase based mass transfer coefficient of DCE $\left(K_{L} a\right)_{\mathrm{oil}}^{\mathrm{DCE}}$ for the absorber was estimated by Koutinas et al. $(2006)\left(5 \times 10^{-5} \mathrm{~s}^{-1}\right)$ and it was assumed that the volumetric mass transfer coefficient for FB $\left(K_{L} a\right)_{\text {oil }}^{\mathrm{FB}}$ has the same value due to the similarities of the two compounds (both DCE and FB can be considered volatile halogenated organics).

\section{System I:BO}

For system I operation, the absorber was not connected and the contaminated gas stream was fed directly to the bioscrubber (Fig. 1), which was operated non-aseptically. During period BO.I, FB (Fig. 2A) and DCE (Fig. 2B) were fed to the $\mathrm{BO}$ configuration continuously at average loading rates of $14 \mathrm{~g}_{\mathrm{FB}} \mathrm{m}^{-3} \mathrm{~h}^{-1}$ and $97 \mathrm{~g}_{\mathrm{DCE}} \mathrm{m}^{-3} \mathrm{~h}^{-1}$. Constant DCE and FB removal efficiencies were observed (more than $80 \%$ removal for both substrates), resulting in outlet loading rates of $1 \mathrm{~g}_{\mathrm{FB}} \mathrm{m}^{-3} \mathrm{~h}^{-1}$ and $14 \mathrm{~g}_{\mathrm{DCE}} \mathrm{m}^{-3} \mathrm{~h}^{-1}$, and biomedium concentrations of $0 \mathrm{~g}_{\mathrm{FB} \mathrm{m}} \mathrm{m}^{-3}$ and $15 \mathrm{~g}_{\mathrm{DCE}} \mathrm{m}^{-3}$ (Fig. 3).

During period BO.II, FB feeding ceased for a period of $72 \mathrm{~h}$ (flow rate $\mathrm{G} 1$ was set to $0 \mathrm{~L} \mathrm{~min}^{-1}$, Fig. 1) while DCE only was fed to the system at the same loading rate as in BO.I. Due to the lack of FB the carbon dioxide concentration was significantly reduced between 0 and $3 \mathrm{~h}$ (Fig. 3) from an average value of $0.68 \% \mathrm{v} / \mathrm{v}$ for period BO.I to $0.45 \% \mathrm{v} / \mathrm{v}$. The reduction of the carbon dioxide concentration continued, but slower between 3 and $72 \mathrm{~h}$, reaching a minimum of $0.37 \% \mathrm{v} / \mathrm{v}$ (time $71 \mathrm{~h}$ ).

At the beginning of period BO.III, the FB load was reintroduced at an average value of $16 \mathrm{~g}_{\mathrm{FB} \mathrm{m}} \mathrm{m}^{-3} \mathrm{~h}^{-1}$ and the DCE feed was stopped for $72 \mathrm{~h}$ (flow rate $\mathrm{G} 2$ was set to $0 \mathrm{~L} \mathrm{~min}^{-1}$, Fig. 1). During period BO.III (Fig. 2A) the FB bioscrubber outlet load increased to $16 \mathrm{~g}_{\mathrm{FB}} \mathrm{m}^{-3} \mathrm{~h}^{-1} 4 \mathrm{~h}$ after the re-introduction of $\mathrm{FB}$ (time $76 \mathrm{~h}$ ), thus reducing the removal efficiency to $0 \%$. The FB bioscrubber outlet load decreased slowly over time to reach $5 \mathrm{~g}_{\mathrm{FB} \mathrm{m}} \mathrm{m}^{-3} \mathrm{~h}^{-1}$ at time $128 \mathrm{~h}$ and
A

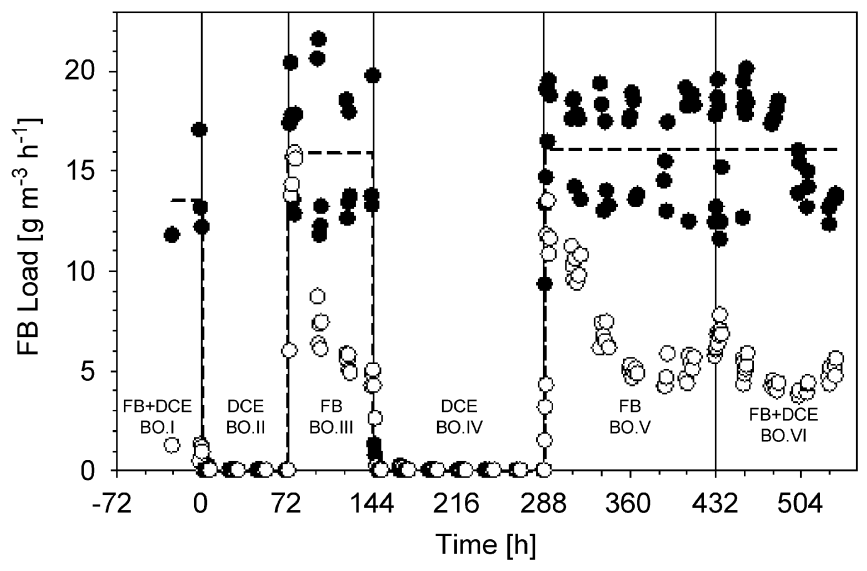

B

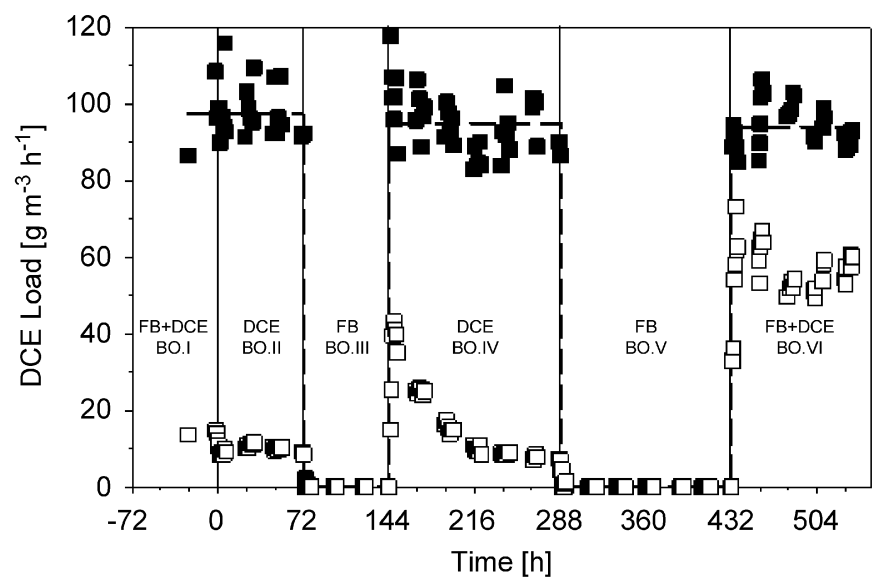

Fig. 2. Evolution of the FB and DCE inlet and outlet loads in the BO system during the SAP experiment. A: FB; B: DCE. •, bioscrubber FB inlet load-experimental; $\mathbf{\square}$, bioscrubber DCE inlet load-experimental; $\circ$, bioscrubber FB outlet load-experimental; $\square$, bioscrubber DCE outlet load-experimental; - - - , bioscrubber FB inlet load-imposed; - - , bioscrubber DCE inlet load-imposed.

the FB removal efficiency increased to reach a maximum of $75 \%$ at time $144 \mathrm{~h}$. Therefore, the FB removal efficiency did not recover to the level of period BO.I ( $>90 \%$ FB removal) even $3 \mathrm{~d}$ after the re-introduction of FB. The carbon dioxide concentration was significantly reduced from $0.37 \% \mathrm{v} / \mathrm{v}$ (time $71 \mathrm{~h}$ ) to $0.17 \% \mathrm{v} / \mathrm{v} 3 \mathrm{~h}$ after $\mathrm{FB}$ re-introduction, and increased slowly over time to $0.25 \%$ at the end of BO.III. Although the biomedium $\mathrm{FB}$ concentration during BO.III remained lower than $3 \mathrm{~g}_{\mathrm{FB}} \mathrm{m}^{-3}$ (Fig. 3), due to the severe increase of the bioscrubber FB outlet load a significant amount of FB was released untreated to the environment.

During period BO.IV the FB feed was stopped for a period of $6 \mathrm{~d}(144 \mathrm{~h})$ and DCE was re-introduced at an average loading rate of $95 \mathrm{~g}_{\mathrm{DCE}} \mathrm{m}^{-3} \mathrm{~h}^{-1}$. Four $\mathrm{h}$ after DCE reintroduction the bioscrubber DCE outlet load increased to a maximum of $43 \mathrm{~g}_{\mathrm{DCE}} \mathrm{m}^{-3} \mathrm{~h}^{-1}$, the biomedium DCE concentration increased to $84 \mathrm{~g}_{\mathrm{DCE}} \mathrm{m}^{-3}$ and the DCE removal efficiency dropped to a minimum of $55 \%$. The system required $2 \mathrm{~d}$ to recover to the initial performance of periods BO.I-II, reducing the 


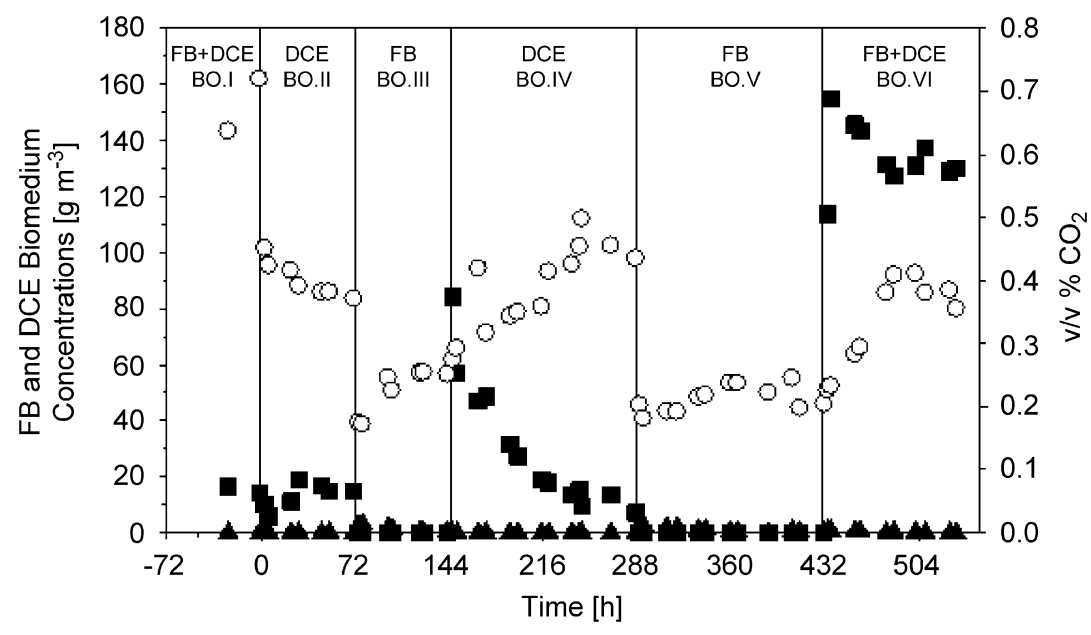

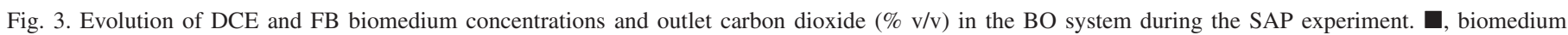
DCE concentration; $\boldsymbol{\Delta}$, biomedium FB concentration; o, outlet carbon dioxide\% v/v.

bioscrubber DCE outlet load to $15 \mathrm{~g}_{\mathrm{DCE}} \mathrm{m}^{-3} \mathrm{~h}^{-1}$ and increasing the DCE removal efficiency to $85 \%$. During period BO.IV the carbon dioxide concentration increased from $0.25 \% \mathrm{v} / \mathrm{v}$ at the beginning of the period to $0.45 \% \mathrm{v} / \mathrm{v}$ at the end (time $288 \mathrm{~h}$ ). However, the carbon dioxide concentration required $3 \mathrm{~d}$ to increase to the same level of period BO.II $(0.37 \% \mathrm{v} / \mathrm{v})$, indicating that the activity of GJ10 cells was reduced during period BO.III when DCE was not supplied.

The feeding of the waste gas was switched again from DCE to $\mathrm{FB}$ during period $\mathrm{BO} . \mathrm{V}$ for $6 \mathrm{~d}$. The bioscrubber $\mathrm{FB}$ inlet load was re-introduced at an average value of $16 \mathrm{~g}_{\mathrm{FB}} \mathrm{m}^{-3} \mathrm{~h}^{-1}$ (time $288 \mathrm{~h}$ ) and the bioscrubber FB outlet load increased to $14 \mathrm{~g}_{\mathrm{FB}} \mathrm{m}^{-3} \mathrm{~h}^{-1}$ after $3 \mathrm{~h}$, causing the FB removal efficiency to drop to a minimum of $18 \%$. The FB removal efficiency increased to $60 \% 2 \mathrm{~d}$ after the re-introduction of FB (time $335 \mathrm{~h}$ ); though it varied between $60 \%$ and $70 \%$ for the rest of the monitoring of the experiment (periods BO.V-VI), failing to reestablish the initial removal efficiency of period BO.I ( $>90 \%$ FB removal). The carbon dioxide concentration was reduced immediately from 0.45 to $0.18 \% \mathrm{v} / \mathrm{v} 5 \mathrm{~h}$ after the re-introduction of $\mathrm{FB}$, and it increased slowly over time to a maximum of $0.24 \%$ $\mathrm{v} / \mathrm{v}$, similarly to period BO.III $(0.25 \% \mathrm{v} / \mathrm{v})$. However, during period BO.III the carbon dioxide concentration required $3 \mathrm{~d}$ to increase to that level, while during period BO.V the increase required $5 \mathrm{~d}$. This suggests that after the $6 \mathrm{~d}$ of FB starvation, F11 needed a longer re-acclimation period to recover after reintroduction of FB, than was required after $3 \mathrm{~d}$ of FB starvation.

Following $6 \mathrm{~d}$ of DCE starvation, the DCE feed was reintroduced at an average value of $94 \mathrm{gDCE} \mathrm{m}^{-3} \mathrm{~h}^{-1}$ (time $432 \mathrm{~h}$ ) maintaining the feeding of $\mathrm{FB}$ at an average value of $16 \mathrm{~g}_{\mathrm{FB}} \mathrm{m}^{-3} \mathrm{~h}^{-1}$. Upon the re-introduction of DCE, the bioscrubber DCE outlet load increased to a maximum value of $73 \mathrm{~g}_{\mathrm{DCE}} \mathrm{m}^{-3} \mathrm{~h}^{-1}$ reducing the DCE removal efficiency to $18 \%$, $4 \mathrm{~h}$ after the restart of the feed. However, for the rest of period BO.VI the DCE removal efficiency showed a relatively small increase to a level between $30 \%$ and $50 \%$, failing to re-establish the initial DCE removal efficiency of period BO.I (90\%). Also, the biomedium DCE concentration followed a similar profile to the bioscrubber DCE outlet load during period BO.VI, increasing to a maximum value of $155 \mathrm{~g}_{\mathrm{DCE}} \mathrm{m}^{-3}, 5 \mathrm{~h}$ after the DCE re-introduction. The biomedium DCE concentration remained at high values for the rest of the experiment $\left(\sim 130 \mathrm{~g}_{\mathrm{DCE}} \mathrm{m}^{-3}\right)$. The carbon dioxide concentration increased from $0.24 \% \mathrm{v} / \mathrm{v}$ at the end of period BO.V to a maximum value of $0.41 \% \mathrm{v} / \mathrm{v}$ $3 \mathrm{~d}$ after the re-introduction of DCE. Nevertheless, the carbon dioxide concentration did not increase any further, failing to restore the average concentration of period BO.I $(0.68 \%$ $\mathrm{v} / \mathrm{v})$. Comparing the performance of the system during periods BO.IV and BO.VI, following $3 \mathrm{~d}$ of DCE starvation (BO.IV) the bioscrubber was able to recover the initial DCE removal of periods BO.I-II, $2 \mathrm{~d}$ after the re-introduction of the substrate. However, after $6 \mathrm{~d}$ of DCE starvation the bioscrubber improved its performance only during the first two days after the re-introduction and remained stable with low DCE removal efficiency for the rest of the experiment.

\section{System II: OAB}

The absorber was placed upstream of the bioscrubber, which was also operated non-aseptically, to act as a buffer for alternating DCE and FB feeding (Fig. 1). The absorber was fed with FB and DCE at average inlet loads of $16 \mathrm{~g}_{\mathrm{FB}} \mathrm{m}^{-3} \mathrm{~h}^{-1}$ and $104 \mathrm{~g}_{\mathrm{DCE}} \mathrm{m}^{-3} \mathrm{~h}^{-1}$, respectively, resulting in average bioscrubber inlet loads of $13 \mathrm{~g}_{\mathrm{FB}} \mathrm{m}^{-3} \mathrm{~h}^{-1}$ and $100 \mathrm{~g}_{\mathrm{DCE}} \mathrm{m}^{-3} \mathrm{~h}^{-1}$ during period OAB.I (Fig. 4). The average values of parameters such as the bioscrubber outlet loads and the removal efficiencies were $2 \mathrm{~g}_{\mathrm{FB}} \mathrm{m}^{-3} \mathrm{~h}^{-1}$ and $86 \%$ for $\mathrm{FB}$, and $24 \mathrm{~g}_{\mathrm{DCE}} \mathrm{m}^{-3} \mathrm{~h}^{-1}$ and $77 \%$ for DCE, respectively. Also, the average biomedium concentrations of the two compounds during period OAB.I were $0 \mathrm{~g}_{\mathrm{FB}} \mathrm{m}^{-3}$ and $45 \mathrm{~g}_{\mathrm{DCE}} \mathrm{m}^{-3}$, while the average value of the carbon dioxide concentration was $0.51 \%$ v/v (Fig. 5).

At the beginning of period OAB.II, the FB feed ceased for $3 \mathrm{~d}$ (flow rate $\mathrm{G} 1$ was set to $0 \mathrm{~L} \mathrm{~min}^{-1}$, Fig. 1) while DCE was fed to the system at the same loading rate as in OAB.I. Thus, 
A

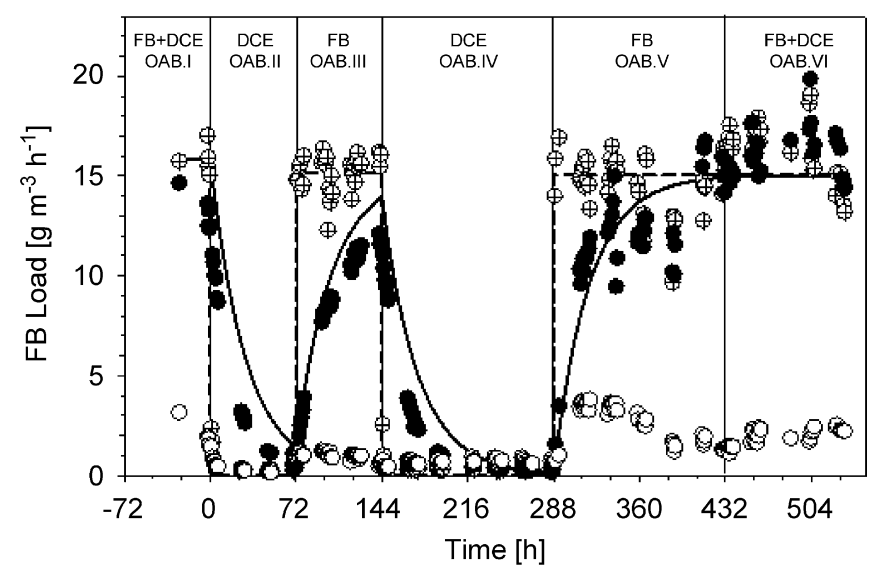

B

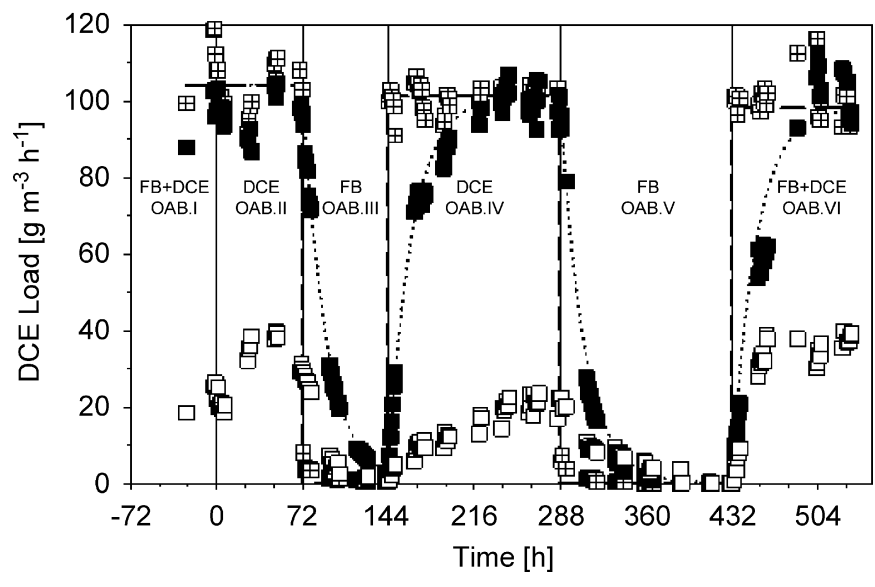

Fig. 4. Evolution of the FB and DCE inlet and outlet loads in the OAB system during the SAP experiment. A: FB; B: DCE. $\oplus$, absorber FB inlet load-experimental; $\boxplus$, absorber DCE inlet load-experimental; •, bioscrubber FB inlet load-experimental; $\boldsymbol{\square}$, bioscrubber DCE inlet load-experimental; o, bioscrubber FB outlet load-experimental; $\square$, bioscrubber DCE outlet load-experimental; ---, absorber FB inlet load-imposed; — — , absorber DCE inlet load—imposed; — $—$, bioscrubber FB inlet load-predicted; ....... bioscrubber DCE inlet load-predicted.

during the $3 \mathrm{~d}$ period that FB was not fed to the system, the FB absorbed into the sunflower oil was desorbed, and the bioscrubber FB inlet load decreased over time to reach a minimum value of $1 \mathrm{~g}_{\mathrm{FB}} \mathrm{m}^{-3} \mathrm{~h}^{-1}$ at the end of OAB.II. The bioscrubber continued to remove the FB fed with an average FB removal efficiency of $92 \%$, although the carbon dioxide concentration did not decrease proportionally to the decrease of the bioscrubber FB inlet load as expected. At $0 \mathrm{~h}$ the biofilm on the walls of the bioscrubber was sampled for microbial analysis, which resulted in a large proportion of the biofilm being suspended in the bioscrubber and washed out over the following few hours of operation. Therefore, although stable DCE removal efficiency and smooth reduction of the carbon dioxide concentration were expected during period OAB.II, these two parameters were reduced abruptly to $60 \%$ and $0.30 \% \mathrm{v} / \mathrm{v}$ for the first $48 \mathrm{~h}$. They recovered only on the last day of OAB.II, reaching $70 \%$ DCE removal efficiency and $0.42 \% \mathrm{v} / \mathrm{v}$ carbon dioxide concentration.
The minimum and maximum FB and DCE removal efficiencies for each period of the two experiments are shown in Table 2.

At $72 \mathrm{~h}$, the FB feed was re-introduced at an average load of $15 \mathrm{~g}_{\mathrm{FB}} \mathrm{m}^{-3} \mathrm{~h}^{-1}$ and the DCE feed ceased for $3 \mathrm{~d}$ (period OAB.III). Due to absorption, the bioscrubber FB inlet load increased slowly over time to reach a maximum value of $12 \mathrm{~g}_{\mathrm{FB}} \mathrm{m}^{-3} \mathrm{~h}^{-1}$ at time $144 \mathrm{~h}$. Thus, the slow increase of the bioscrubber FB inlet load allowed sufficient time for strain F11 to grow in the bioscrubber, resulting in low values of bioscrubber FB outlet load during period OAB.III. The bioscrubber FB outlet load did not increase more than $1 \mathrm{~g}_{\mathrm{FB}} \mathrm{m}^{-3} \mathrm{~h}^{-1}$ showing that strain F11 remained active during the $3 \mathrm{~d}$ of FB starvation. Therefore, the bioscrubber was able to restore FB removal efficiency similar to period OAB.I during the whole OAB.III period (up to $95 \%$ FB removal efficiency achieved), contrary to the poor FB removal efficiency achieved in the BO system (period BO.III). Furthermore, due to the lack of DCE from the process inlet, the bioscrubber DCE inlet load was reduced over time to reach a minimum of $3 \mathrm{~g}_{\mathrm{DCE}} \mathrm{m}^{-3} \mathrm{~h}^{-1}$ at time $144 \mathrm{~h}$. The bioscrubber DCE outlet load and the biomedium DCE concentration decreased to $0 \mathrm{~g}_{\mathrm{DCE}} \mathrm{m}^{-3} \mathrm{~h}^{-1}$ and $0 \mathrm{~g}_{\mathrm{DCE}} \mathrm{m}^{-3}$, respectively. Also, the carbon dioxide concentration decreased over time to reach a minimum of $0.25 \% \mathrm{v} / \mathrm{v}$.

After $3 \mathrm{~d}$ of DCE starvation, the DCE feed was re-introduced at an average loading of $101 \mathrm{~g}_{\mathrm{DCE}} \mathrm{m}^{-3} \mathrm{~h}^{-1}$ and the FB feed was simultaneously stopped for $6 \mathrm{~d}$ (OAB.IV). Similarly to the reintroduction of FB (period OAB.III), the bioscrubber DCE inlet load increased slowly over time and after $3 \mathrm{~d}$ reached the level of the absorber DCE inlet load. The bioscrubber DCE outlet load increased slowly over time during period OAB.IV, to reach a maximum value of $23 \mathrm{~g}_{\mathrm{DCE}} \mathrm{m}^{-3} \mathrm{~h}^{-1}$ at the end of OAB.IV. The biomedium DCE concentration followed the same profile as the bioscrubber DCE outlet load, reaching a maximum value of $61 \mathrm{~g}_{\mathrm{DCE}} \mathrm{m}^{-3}$. The DCE removal efficiency was higher than $77 \%$ during OAB.IV, showing that the re-introduction of DCE did not deteriorate the performance of the bioscrubber compared to period OAB.I. On the other hand, the bioscrubber FB inlet load was reduced over time to $1 \mathrm{~g}_{\mathrm{FB}} \mathrm{m}^{-3} \mathrm{~h}^{-1}$, approximately $3 \mathrm{~d}$ after the interruption of the FB feed. However, during the last $3 \mathrm{~d}$ of period OAB.IV, FB was still detected in the bioscrubber inlet and was fed into the bioscrubber at loads ranging between 0.2 and $1 \mathrm{~g}_{\mathrm{FB}} \mathrm{m}^{-3} \mathrm{~h}^{-1}$. The carbon dioxide concentration increased over time due to the re-introduction of DCE and reached a maximum value of $0.53 \% \mathrm{v} / \mathrm{v}$.

At $288 \mathrm{~h}$, the FB feed was resumed at an average loading rate of $15 \mathrm{~g}_{\mathrm{FB}} \mathrm{m}^{-3} \mathrm{~h}^{-1}$ and the DCE feed was stopped for a period of $6 \mathrm{~d}$. The bioscrubber FB inlet load increased slowly over time due to the absorption of FB in the oil and equalised to the absorber FB inlet load after approximately $3 \mathrm{~d}$. Once again the effect of the absorber was beneficial for strain F11, showing that even a very low load of FB fed constantly to the bioscrubber during the starvation period (less than $1 \mathrm{~g}_{\mathrm{FB}} \mathrm{m}^{-3} \mathrm{~h}^{-1}$ ), was able to maintain the strain active. Therefore, the bioscrubber FB outlet load increased to $4 \mathrm{~g}_{\mathrm{FB}} \mathrm{m}^{-3} \mathrm{~h}^{-1}$ for the first two days after the re-introduction of $\mathrm{FB}$ and was reduced to a level between 1 and $2 \mathrm{~g}_{\mathrm{FB}} \mathrm{m}^{-3} \mathrm{~h}^{-1}$ by the end of period OAB.V. The biomedium $\mathrm{FB}$ concentration was $0 \mathrm{~g}_{\mathrm{FB}} \mathrm{m}^{-3}$ at all times and 


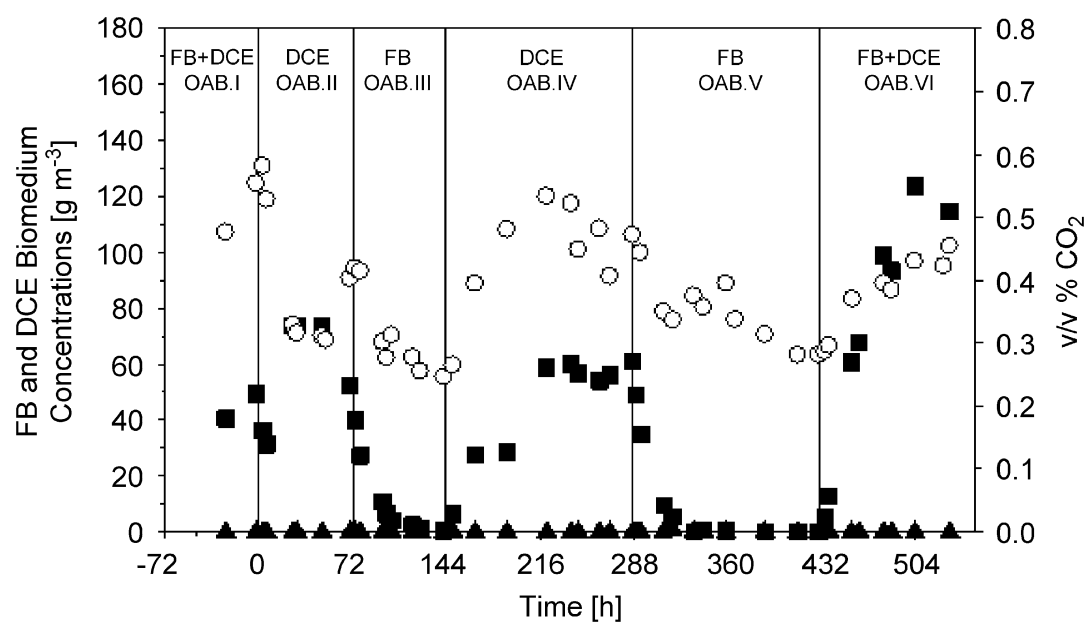

Fig. 5. Evolution of DCE and FB biomedium concentrations and outlet carbon dioxide (\% v/v) in the OAB system during the SAP experiment. $\mathbf{\square}$, biomedium DCE concentration; $\boldsymbol{\Lambda}$, biomedium FB concentration; o, outlet carbon dioxide $\%$ v/v.

Table 2

Minimum and maximum FB and DCE removal efficiencies for each period of the $\mathrm{BO}$ and $\mathrm{OAB}$ systems

\begin{tabular}{lllllll}
\hline & BO.I & BO.II & BO.III & BO.IV & BO.V & BO.VI \\
\hline FB $^{\mathrm{a}}$ & $90-97$ & 0 & $0-75$ & 0 & $18-75$ & $33-78$ \\
DCE $^{\mathrm{a}}$ & $84-88$ & $88-91$ & 0 & $55-93$ & 0 & $18-49$ \\
& OAB.I & OAB.II & OAB.III & OAB.IV & OAB.V & OAB.VI \\
\hline FB $^{\mathrm{a}}$ & $79-88$ & $89-95$ & $53-95$ & $76-95$ & $66-92$ & $84-93$ \\
DCE $^{\mathrm{a}}$ & $74-78$ & $54-80$ & $66-91$ & $74-91$ & $49-78$ & $33-72$ \\
\hline
\end{tabular}

${ }^{\mathrm{a}} \mathrm{FB}$ and DCE removal efficiency values are given as a percentage of the influent FB and DCE loading values to each system.

the FB removal efficiency had a minimum value of $66 \%$ during the first $2 \mathrm{~d}$; though, the FB removal efficiency increased to a maximum of $92 \%$ at the end of period OAB.V. The bioscrubber DCE inlet load was reduced over time during period OAB.V and reached $1 \mathrm{gDCE} \mathrm{m}^{-3} \mathrm{~h}^{-1}$ approximately $3 \mathrm{~d}$ after the interruption of the DCE feed. However, DCE was still supplied to the bioscrubber at a very low loading that ranged between 0.3 and $1 \mathrm{~g}_{\mathrm{DCE}} \mathrm{m}^{-3} \mathrm{~h}^{-1}$, for the remaining $3 \mathrm{~d}$ of DCE starvation. The carbon dioxide concentration was reduced over time and reached a minimum value of $0.28 \% \mathrm{v} / \mathrm{v}$ at the end of OAB.V.

During period OAB.VI, the DCE feed was re-introduced at $98 \mathrm{~g}_{\mathrm{DCE}} \mathrm{m}^{-3} \mathrm{~h}^{-1}$ and the FB feed was maintained at the same loading rate as in OAB.V $\left(15 \mathrm{~g}_{\mathrm{FB}} \mathrm{m}^{-3} \mathrm{~h}^{-1}\right)$. After the re-introduction of DCE, the bioscrubber DCE inlet load increased over time to reach the level of the absorber DCE inlet load after approximately $3 \mathrm{~d}$. The bioscrubber DCE outlet load increased to a maximum value of $38 \mathrm{~g}_{\mathrm{DCE}} \mathrm{m}^{-3} \mathrm{~h}^{-1} 1 \mathrm{~d}$ after the restart of the DCE feed and maintained that level for the next days of monitoring. The biomedium DCE concentration increased to a maximum value of $123 \mathrm{gDCE}^{-3}$ and the DCE removal efficiency decreased to a minimum value of $33 \%$ at time $461 \mathrm{~h}$. However, the DCE removal efficiency increased for the next days of monitoring to a level between $60 \%$ and $70 \%$.
The carbon dioxide concentration increased over time to $0.45 \%$ $\mathrm{v} / \mathrm{v}$ after $4 \mathrm{~d}$, while for the whole duration of OAB.VI period the bioscrubber maintained similar FB removal as in period OAB.V.

The expected and measured concentrations of $\mathrm{F}^{-}$and $\mathrm{Cl}^{-}$ anions in the bioscrubber were also monitored during the SAP experiment in the $\mathrm{BO}$ and $\mathrm{OAB}$ systems (data not shown). The expected concentrations were in agreement with the measured values in the two systems, implying that complete dehalogenation of the two substrates was taking place at all times.

It is now interesting to verify whether the mathematical model for the absorber, developed in our previous study (Koutinas et al., 2007) involving absorption of DCE only will also describe successfully the SAP experiment. The experimental and modelling results are presented in Fig. 4. The bioscrubber DCE inlet load predicted by the model overlaps the experimental results during the SAP experiment at all times. Furthermore, the prediction of the model for the bioscrubber FB inlet load is in general agreement with the experimental results. During period OAB.II the bioscrubber FB inlet load was reduced to a minimum value of $1 \mathrm{~g}_{\mathrm{FB}} \mathrm{m}^{-3} \mathrm{~h}^{-1}$ at $72 \mathrm{~h}$, while that predicted by the model value was $2 \mathrm{~g}_{\mathrm{FB}} \mathrm{m}^{-3} \mathrm{~h}^{-1}$. Also, the maximum value of the bioscrubber FB inlet load predicted at time $144 \mathrm{~h}$ was $14 \mathrm{~g}_{\mathrm{FB} \mathrm{m}} \mathrm{m}^{-3} \mathrm{~h}^{-1}$, while the value measured experimentally was $12 \mathrm{~g}_{\mathrm{FB}} \mathrm{m}^{-3} \mathrm{~h}^{-1}$. During period OAB.IV the bioscrubber FB inlet load was reduced to $1 \mathrm{~g}_{\mathrm{FB}} \mathrm{m}^{-3} \mathrm{~h}^{-1}$ approximately $2 \mathrm{~d}$ after stopping the FB feed to the absorber, whilst the model predicted that the load would be reduced to that value after $3 \mathrm{~d}$. However, during the re-introduction of FB in period OAB.V, the bioscrubber FB inlet load predicted by the model was in fair agreement with the experimental results. The small discrepancy between the predicted and observed absorption/desorption behaviour of FB could be due to the assumption made that FB and DCE have the same volumetric mass-transfer coefficient in the absorber, but also to the much bigger scattering of the FB inlet concentration, which was difficult to stabilise. In general we can conclude that the model 
A

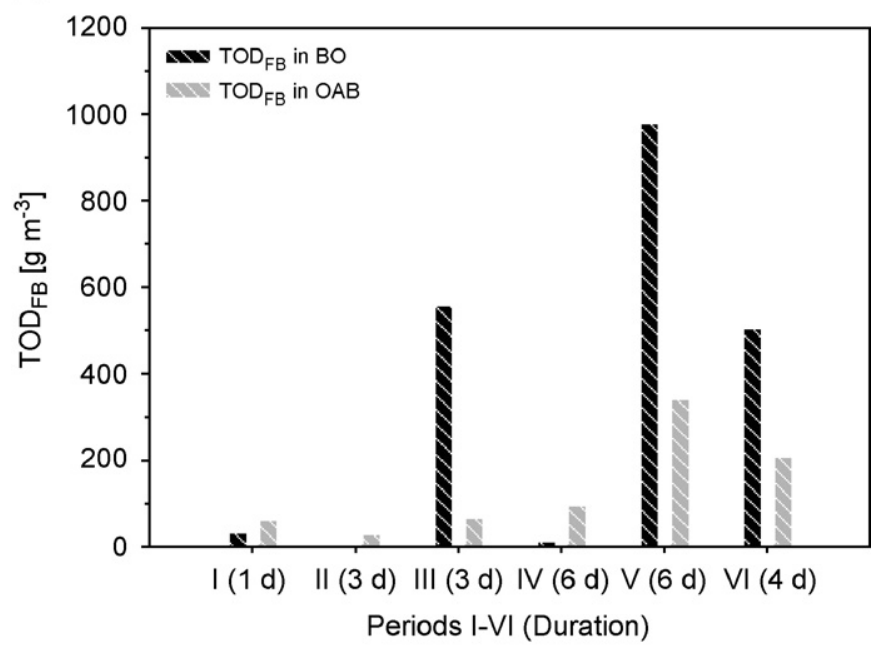

B

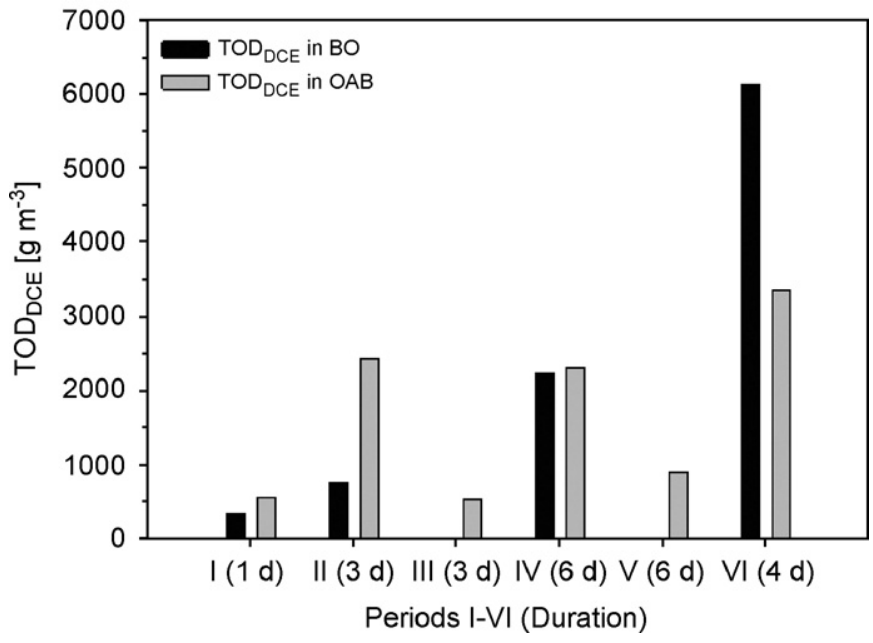

Fig. 6. Total organic mass discharged during each period of the $\mathrm{BO}$ and $\mathrm{OAB}$ systems. The mass of FB and DCE discharged was calculated for each period by integrating the effluent FB and DCE concentrations multiplied by the flowrates of the gas and biomedium outlets of the bioscrubber and normalised by the bioscrubber volume. The duration of each period is displayed in brackets. A: TOD $\mathrm{FB}$; B: TOD $\mathrm{DCE}$.

is fairly applicable to the SAP system. It would be also very interesting to describe the operation of the bioscrubber unit of the two systems mathematically. However, this option was not possible for the time being due to the fact that very limited work has been published on the biodegradation of FB by strain F11 up to date, and various model parameters have not been estimated experimentally. This part of the mathematical modelling will be investigated later in a separate study.

Fig. 6 shows the total organic mass discharged as FB $\left(\mathrm{TOD}_{\mathrm{FB}}\right)$ and $\mathrm{DCE}\left(\mathrm{TOD}_{\mathrm{DCE}}\right)$ from the $\mathrm{BO}$ and $\mathrm{OAB}$ systems during each period. The FB re-introduction periods caused much higher $\mathrm{TOD}_{\mathrm{FB}}$ from the $\mathrm{BO}$ system than from the OAB system $($ BO.III $\sim 557$, BO.V $\sim 979$, BO.VI $\sim$ $504 \mathrm{~g}_{\mathrm{FB}} \mathrm{m}^{-3}$ vs OAB.III $\sim 65$, OAB.V $\sim 339$, OAB.VI $\sim$ $205 \mathrm{~g}_{\mathrm{FB}} \mathrm{m}^{-3}$ ). Thus, the addition of the absorber prior to the bioscrubber, significantly reduced the discharges of FB (up to 9 times for period OAB.III). On the contrary, as shown in Fig. $6 \mathrm{~B}$ the TOD $\mathrm{DCE}_{\mathrm{DC}}$ during the operation of the $\mathrm{OAB}$ system was similar or even higher than the $\mathrm{TOD}_{\mathrm{DCE}}$ from the $\mathrm{BO}$ system.

This result is in contrast to the results obtained from the DCE starvation experiments performed by Koutinas et al. (2007) in a similar OAB system. The discharges of DCE were not reduced during the $\mathrm{OAB}$ operation, perhaps due to a possible inhibitory effect on GJ10 caused by FB itself or by metabolic products from FB degradation. Carvalho et al. (2006a) reported that FB loads in the range of 9-11 $\mathrm{g} \mathrm{m}^{-3} \mathrm{~h}^{-1}$ applied in an up-flow fixed bed reactor impacted negatively on the biological removal efficiency of the system. This fact was attributed to a possible inhibitory effect on the microbial biofilm caused by the higher FB concentrations fed to the system, but was not further investigated. The system used in our study was able to efficiently treat slightly higher FB loads than the system used by Carvalho et al. (2006a). The preliminary tests of the degradation capabilities of F11 and GJ10 for FB and DCE performed in shake flasks showed that F11 and GJ10 cannot utilise each-others substrate as a sole carbon and energy source. However, both strains are able to grow on their specific substrate, even in the presence of $2 \mathrm{mM}$ of the second substrate that they cannot degrade (see Table 1). In addition, the concentration of FB in the biomedium during the whole SAP experiment was negligible $\left(3 \mathrm{mg} \mathrm{L}^{-1}\right.$ maximum FB concentration). These results suggest that the inhibition is due to metabolic products from FB biodegradation rather than to FB itself. Thus, although the absorber reduced the peak concentrations of FB influent to the bioscrubber during the FB re-introduction periods, this was not sufficient to avoid the inhibitory metabolite effect. Furthermore, the presence of FB in the bioscrubber inlet persisted for prolonged periods in the OAB system due to the effect of the absorber, in turn prolonging the periods of exposure to the metabolic products of FB degradation, and thus extending the inhibition periods of DCE degradation and increasing the TOD ${ }_{\mathrm{DCE}}$ for the system.

In light of the above conclusions, it was decided to investigate the inhibitory effect in more detail. Carvalho et al. (2006b) showed that 4-fluorocatechol and catechol are formed as intermediates during FB degradation by strain F11 cells. However, since $\mathrm{F}^{-}$is the final degradation product and $\mathrm{F}^{-}$release is taking place already during the initial period of FB degradation (Carvalho et al., 2006b), only the effect of $\mathrm{F}^{-}$concentration on the growth of GJ10 was studied.

\section{Effect of F- on GJ10}

The effect of increasing concentrations of $\mathrm{F}^{-}$anions on GJ10 was studied in shake flasks as described in the Materials and Methods section. Fig. 7 displays the $\mathrm{Cl}^{-}$concentration, the dry cell weight and the biomedium DCE concentration $20 \mathrm{~h}$ after the inoculation of $\mathrm{F}^{-}$supplemented DCE medium with strain GJ10. It is clear that as $\mathrm{F}^{-}$concentration increases, the release of $\mathrm{Cl}^{-}$anions and the dry cell weight decreases, and higher concentrations of DCE remain untreated in the biomedium. The percentage of $\mathrm{Cl}^{-}$released, given by the 


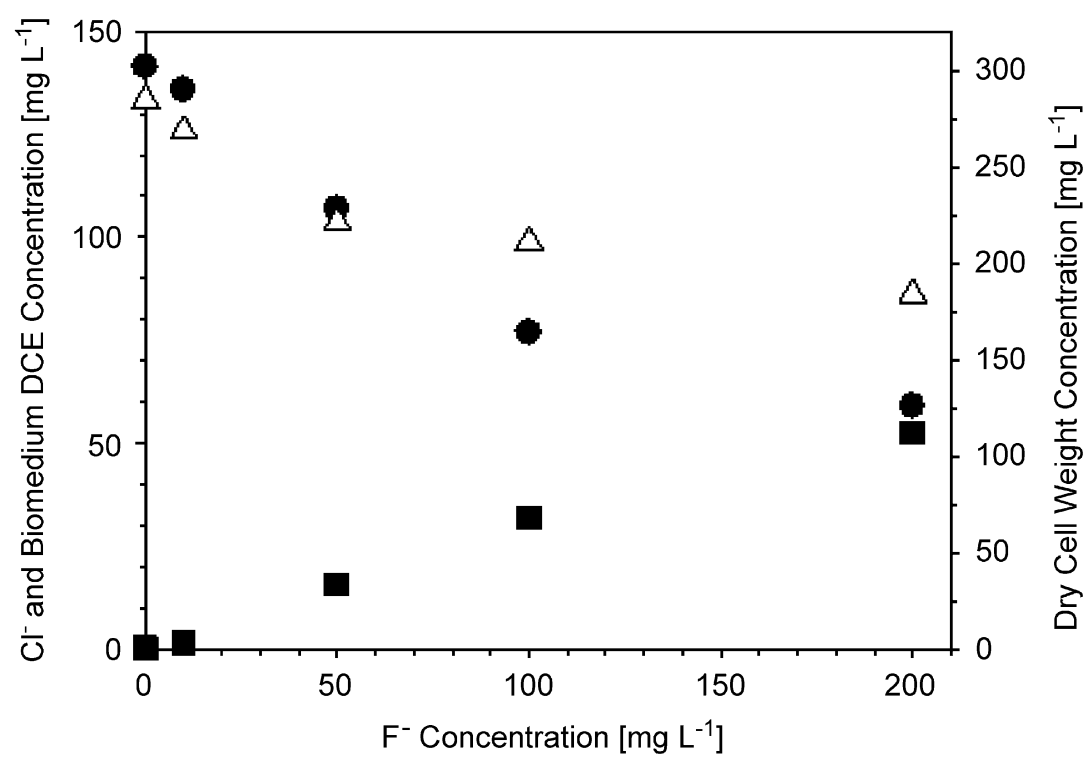

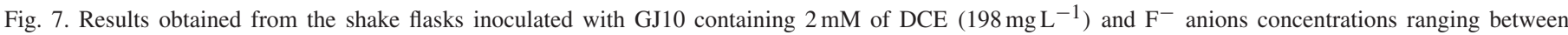

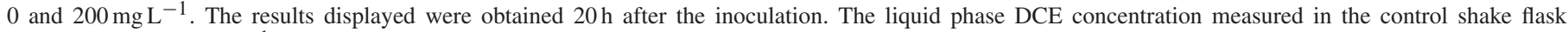
after $20 \mathrm{~h}$ was $174 \mathrm{mg} \mathrm{L}^{-1} . \triangle, \mathrm{Cl}^{-}$concentration; $\mathbf{\square}$, biomedium DCE concentration; $\bullet$, dry cell weight concentration.

formula in brackets (percentage of $\mathrm{Cl}^{-}$released $=100 \% \times \mathrm{Cl}^{-}$ concentration measured $/ \mathrm{Cl}^{-}$concentration expected for complete dehalogenation) was $94 \%$ for $0 \mathrm{mg} \mathrm{F}^{-} \mathrm{L}^{-1}, 70 \%$ for $100 \mathrm{mg} \mathrm{F}^{-} \mathrm{L}^{-1}$ and $61 \%$ for $200 \mathrm{mg} \mathrm{F}^{-} \mathrm{L}^{-1}$. This indicates that even $\mathrm{F}^{-}$concentrations lower than $200 \mathrm{mg} \mathrm{L}^{-1}$, which was the range of $\mathrm{F}^{-}$concentration in the bioscrubber during the $\mathrm{BO}$ and OAB experiments, can slow DCE degradation by GJ10.

During periods BO.VI and OAB.VI in the two systems, the worst DCE degradation coincided with the highest sustained $\mathrm{F}^{-}$concentration (data not shown). However, apart from the inhibitory effect of $\mathrm{F}^{-}$, it is also possible that other metabolites from FB degradation (such as 4-fluorocatechol and catechol) can be inhibitory for GJ10 growth. Since the study of the inhibitory effect is out of the scope of this paper, further tests were not performed.

\section{Analysis of bioscrubber microbial dynamics using FISH \\ Evolution o fthe cellular activity}

The relationship between the operational stability of the two systems (BO and $\mathrm{OAB}$ ) and the behaviour of the microbial population was monitored during the SAP experiments. Fig. 8A,B displays the evolution of active cells ( $\%$ of active cells $=100 \% \times$ EUB stained cells/DAPI stained cells) in both systems tested and indicates that significant changes in cellular activity occurred during the SAP experiment. When the FB feed was stopped at $0 \mathrm{~h}$, the percentage of active cells increased from an average value of $62 \%$ during period BO.I to a maximum value of $91 \%$ at the end of BO.II. Switching the substrate feed from DCE to FB in period BO.III caused a significant reduction of cellular activity which decreased to a minimum of $46 \%$ at $144 \mathrm{~h}$. However, activity increased slightly during period BO.IV when only DCE was fed to the bioscrubber, and decreased again to a minimum value of $37 \%$ during period BO.V when only FB was fed. During the last period of the SAP experiment (BO.VI) when both substrates were fed, the percentage of active cells remained constant at an average value of $36 \%$. The $t$-test was applied to the activity results using MS Excel ${ }^{\mathrm{TM}}$ and typical threshold values for rejection of the starting hypothesis: $P=0.05$ (level of significance), $P=0.01$ (highly significant) and $P=0.001$ (very highly significant). $T$-test results indicate that for periods BO.II and BO.III the increase and decrease observed in cellular activity, respectively (Fig. 8A) is statistically significant $(P<0.05)$. However, for periods BO.IV-BO.VI the changes observed in cellular activity are not significantly different $(P>0.05)$.

The activity of the biofilm formed in the bioscrubber due to wall growth was also measured before and after the SAP experiment. At time $0 \mathrm{~h}$ the cellular activity in the biofilm was $66 \%$ and at time $528 \mathrm{~h}$ it was $45 \%$. The activity of cells was reduced in the biofilm during the SAP experiment, which is in agreement with the overall reduction in the suspended cell activity at the same time. The evolution of active cells in the BO system shows that a significant reduction in the cellular activity occurred when only FB was fed (BO.III and BO.V), in agreement with the hypothesis of the inhibitory effect caused by FB metabolites (e.g. $\mathrm{F}^{-}$).

The response of cell activity during the SAP experiment was different for the OAB system (Fig. 8B). The average value of the activity prior to the first starvation cycle (OAB.I) was $42 \%$ and switching the feed sequentially to only DCE (OAB.II) or only FB (OAB.III) for $3 \mathrm{~d}$ did not change this value significantly. However, the cellular activity started to increase at time $216 \mathrm{~h}, 3 \mathrm{~d}$ after stopping the FB feed for a second time (OAB.IV), reaching a value of $84 \%$ at time $336 \mathrm{~h}$. The activity dropped again $4 \mathrm{~d}$ after switching to FB during OAB.V, to 
A

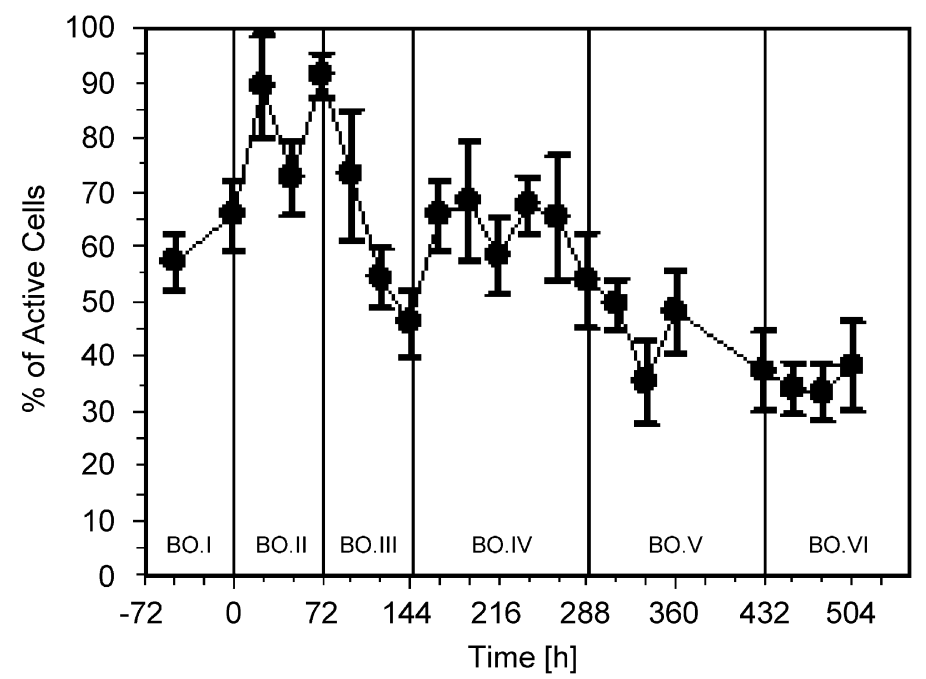

B

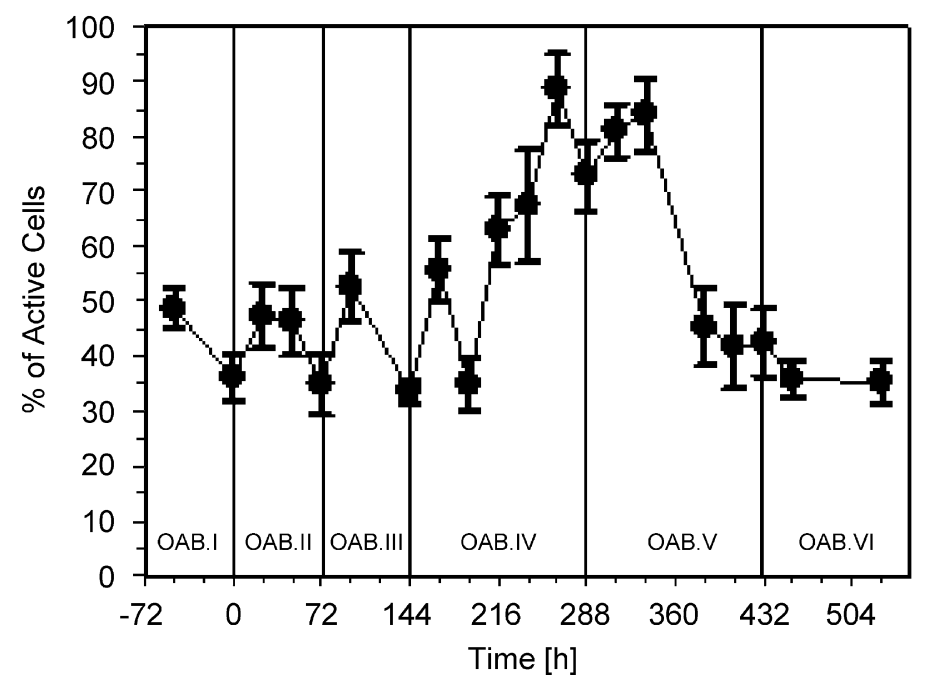

C

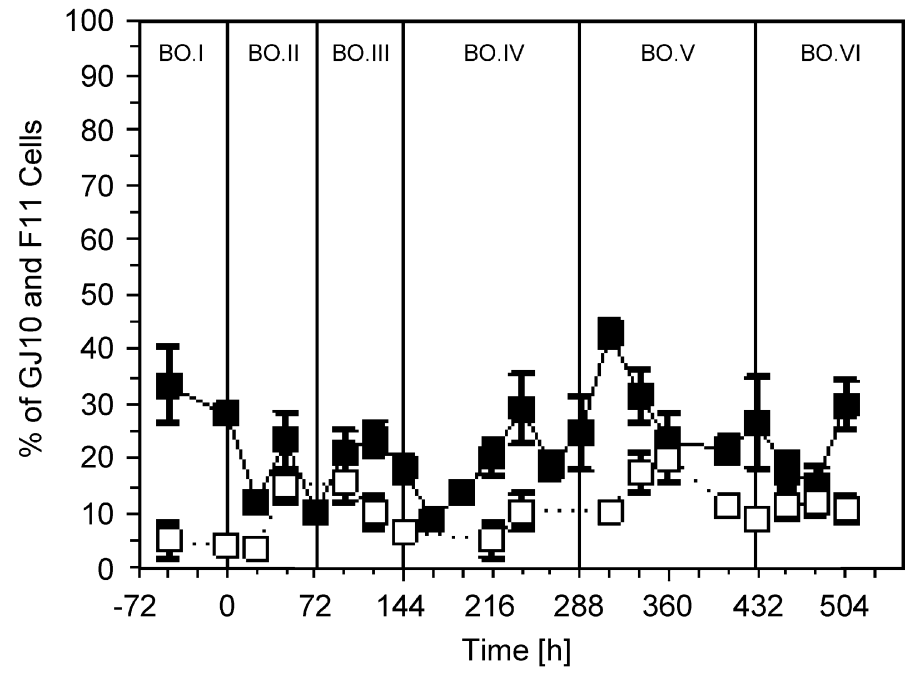

D

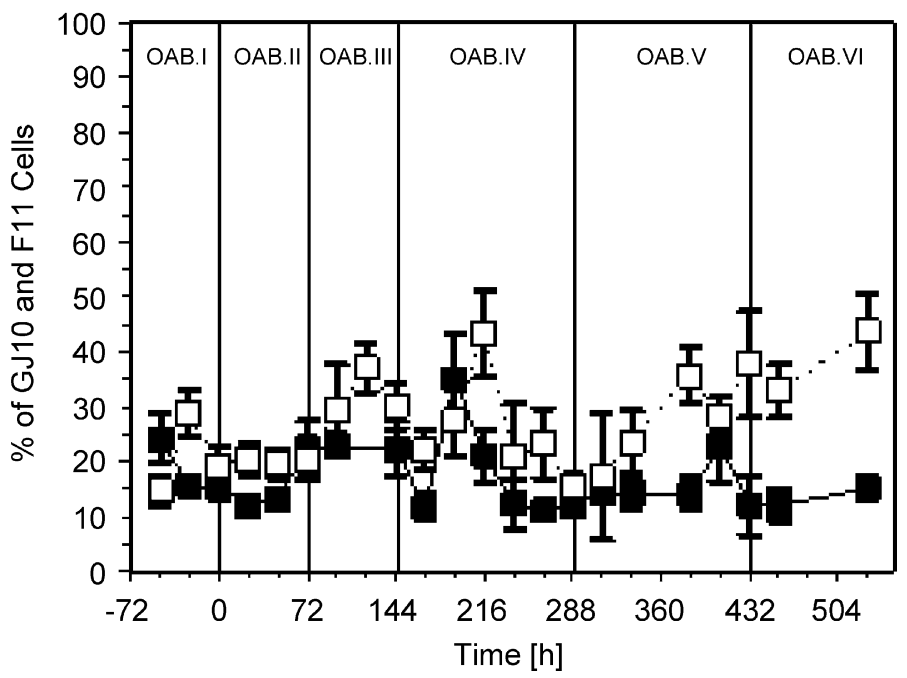

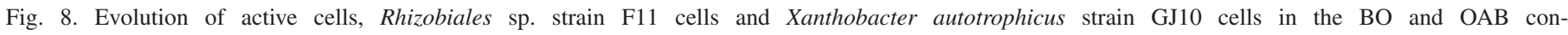

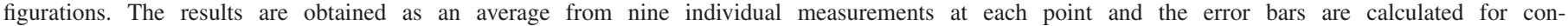

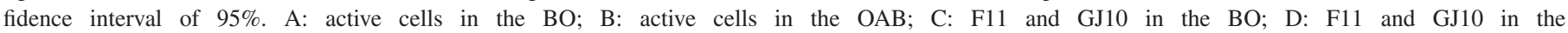

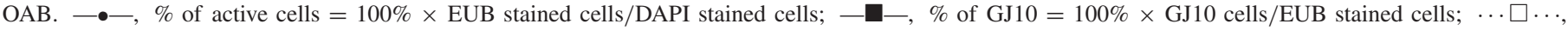
$\%$ of $\mathrm{F} 11=100 \% \times \mathrm{F} 11$ cells $/$ EUB stained cells.

a level of $42 \%$ at time $432 \mathrm{~h}$. The feeding of both substrates during period OAB.VI did not change the activity significantly from an average value of $36 \%$. Furthermore, $t$-test analysis indicates that the values of cellular activity between 240 and $336 \mathrm{~h}$ are statistically higher than the values between -48 to $216 \mathrm{~h}$ and 384-528 h. Likewise, the values between 384 and $528 \mathrm{~h}$ were not statistically different from the values between -48 and $216 \mathrm{~h}$, indicating that the cellular activity was reduced to the initial level.

Overall, the activity of cells in suspension for the OAB system before and after the SAP experiment was the same. This is in agreement with the activity of the cells growing as a biofilm on the walls of the bioscrubber which also remained relatively constant before and after the SAP experiment $(24 \%$ at time $0 \mathrm{~h}$ and $30 \%$ at time $528 \mathrm{~h}$ ). In contrast to the BO operation, the results presented above show that during the $3 \mathrm{~d}$ sequential periods of DCE and FB starvation (OAB.II-III) the activity of the cells did not change significantly. This was attributed to the absorber continuing to feed both substrates to the bioscrubber at significant rates during the whole duration of periods OAB.II-III, maintaining the activity of the microbial culture constant. However, during the $6 \mathrm{~d}$ sequential periods of DCE and FB starvation (OAB.IV-V) the activity of cells increased when only DCE was fed, and decreased when only FB was fed. These changes occurred 3-4 d after switching the substrate feed, in contrast to the BO experiment in which they occurred immediately after changing the conditions.

As a general trend for both systems, the activity of the microbial culture shifted up during the periods that only DCE was fed and shifted down during the periods that only FB was fed. This 
confirms the inhibitory effect of metabolites produced from FB degradation (such as $\mathrm{F}^{-}$anions) on the microbial culture, reducing the cellular activity when FB was fed. Furthermore, comparing the results shown in Fig. 8A,B with the measured $\mathrm{F}^{-}$concentration during the experiments (data not shown), the increase of cellular activity in both systems coincides with the $\mathrm{F}^{-}$concentration drop below $20 \mathrm{~g} \mathrm{~m}^{-3}$.

\section{Evolution of Rhizobiale ssp. Strain F11 and Xanthobac- ter autotrophicus strain GJ10}

The evolution of Rhizobiales sp. strain F11 and Xanthobacter autotrophicus strain GJ10 was monitored during the SAP experiments in the $\mathrm{BO}$ and $\mathrm{OAB}$ configurations (Fig. 8C,D). The percentage of each strain was calculated using the following formula:\% of GJ10 or F11 = 100\% $\times$ GJ10 or F11 cells/EUB stained cells. The percentage of each strain was expected to decrease during the periods that the specific substrate was not supplied, and to increase during the feeding periods of the specific substrate. However, the results did not seem to follow that trend, and were rather scattered over time in both systems. The percentage of the specific degraders (added together) was rather low compared to the total number of active cells in the bioscrubber and did not reach more than 55\% in the BO system, or more than $65 \%$ in the OAB system.

The low percentages of the two specific degraders indicate that dynamic microbial communities were formed in the bioscrubber during the operation of the two systems, and microorganisms apart from the two specific degraders seem to be growing in the microbial culture. The origin of these bacteria has not yet been determined and whether they take part in the FB and DCE degradation, or feed on other metabolites produced by the main degraders, would be an interesting subject for further investigations. This is in agreement with the findings of Carvalho et al. (2006a) who identified the presence of nine different bacterial strains as well as the original inoculum (strain F11) growing in the bioreactor used for the degradation of FB.

In both systems the distribution of the two specific degraders in the biofilm growing on the walls of the bioscrubber was similar to the percentages of the two degraders in the suspended culture. In the BO system the percentages of GJ10 and F11 in the biofilm were $13 \%$ and $4 \%$, respectively, at time $0 \mathrm{~h}$, while at time $528 \mathrm{~h}$ these percentages were $12 \%$ and $7 \%$. In the OAB system, the percentages of GJ10 and F11 in the biofilm were $20 \%$ and $24 \%$ at time $0 \mathrm{~h}$, while at time $528 \mathrm{~h}$ GJ10 and F11 were $28 \%$ and $48 \%$, respectively. It was expected that due to the inhibitory effect of $\mathrm{F}^{-}, \mathrm{GJ} 10$ exposed to stress conditions would mainly grow in the biofilm. However, this was not the case and the percentages of the two specific strains in the biofilm and in suspension were similar. Despite the scattering of the results, there is a tendency towards increase of the percentage of F11 population by the end of the OAB system experiment (OAB.V, OAB.VI). This tendency is also confirmed by the analysis of the biofilm composition. We speculate that due to the $\mathrm{F}^{-}$accumulation in the $\mathrm{OAB}$ system during the last two periods (data not shown), the growth of species other than F11 was suppressed, while F11 was eventually able to tolerate $\mathrm{F}^{-}$concentrations and grow adequately. Thus the $\mathrm{F}^{-}$concentration seems to have a major impact on the overall system performance.

\section{Conclusions}

The results of the present work have shown that:

- $\mathrm{F}^{-}$is inhibitory for GJ10 strain at concentrations as low as $50 \mathrm{mg} \mathrm{L}^{-1}$.

- The OAB system may not be as efficient as expected in smoothing SAP cycles. When an inhibitory metabolite from biodegradation of the pollutant is formed, the inhibitor persists in the system for longer periods due to the absorber. However, although no improvement of the DCE removal efficiency could be observed, due to the significant improvement in the degradation of $\mathrm{FB}$, overall, the $\mathrm{OAB}$ system shows a better performance for the degradation of the two model compounds than the BO.

- The inhibitory effect on the BO and OAB systems can be successfully monitored via measurements of the cellular activity determined using the FISH technique.

- The OAB system may be a good solution for treating waste streams presenting SAP where the metabolic products from pollutant degradation does not adversely affect the microbial activity. This was demonstrated by the successful reduction of the TOD $\mathrm{FB}_{\mathrm{FB}}$ during the SAP experiment in the OAB system.

- The mathematical model of the absorber developed in our previous work was applicable for the description of the absorption-desorption FB and DCE cycles during the SAP experiment.

\section{Notation}

\begin{tabular}{|c|c|}
\hline$C_{a, \text { in }}^{\mathrm{DCE}}$ & $\begin{array}{l}\text { absorber inlet DCE gas phase concentra- } \\
\text { tion, } \mathrm{mg} \mathrm{L}^{-1}\end{array}$ \\
\hline$C_{a \text {,in }}^{\mathrm{FB}}$ & $\begin{array}{l}\text { absorber inlet FB gas phase concentration, } \\
\mathrm{mg} \mathrm{L}^{-1}\end{array}$ \\
\hline$C_{a, \mathrm{out}}^{\mathrm{DCE}}$ & $\begin{array}{l}\text { absorber outlet (or bioscrubber inlet) DCE } \\
\text { gas phase concentration, } \mathrm{mg} \mathrm{L}^{-1}\end{array}$ \\
\hline$C_{a, \text { out }}^{\mathrm{FB}}$ & $\begin{array}{l}\text { absorber outlet (or Bioscrubber Inlet) FB } \\
\text { gas phase concentration, } \mathrm{mg} \mathrm{L}^{-1}\end{array}$ \\
\hline$C_{G, \mathrm{FB}}$ & $\begin{array}{l}\text { gas phase } \mathrm{FB} \text { concentration in equilibrium } \\
\text { with oil } \mathrm{FB} \text { concentration, } \mathrm{mg} \mathrm{L}^{-1}\end{array}$ \\
\hline$C_{\text {sun,oil }}^{\mathrm{DCE}}$ & $\begin{array}{l}\text { DCE concentration in sunflower oil, } \\
\mathrm{mg} \mathrm{L}^{-1}\end{array}$ \\
\hline$C_{\text {sun,oil }}^{\mathrm{FB}}$ & $\begin{array}{l}\text { FB concentration in sunflower oil, } \\
\mathrm{mg} \mathrm{L}^{-1}\end{array}$ \\
\hline$G$ & total gas flow rate, $\mathrm{L} \mathrm{s}^{-1}$ \\
\hline$\left(K_{L} a\right)_{\mathrm{oil}}^{\mathrm{DCE}}$ & $\begin{array}{l}\text { volumetric mass transfer coefficient for } \\
\text { DCE in the absorber, } s^{-1}\end{array}$ \\
\hline$\left(K_{L} a\right)_{\mathrm{oil}}^{\mathrm{FB}}$ & $\begin{array}{l}\text { volumetric mass transfer coefficient for } \\
\text { FB in the absorber, } s^{-1}\end{array}$ \\
\hline$P$ & observed significance, dimensionless \\
\hline$P_{\text {sun,oil }}^{\mathrm{DCE}}$ & $\begin{array}{l}\text { partition coefficient for DCE between sun- } \\
\text { flower oil and air, dimensionless }\end{array}$ \\
\hline
\end{tabular}




\begin{tabular}{|c|c|}
\hline$P_{\text {sun, oil }}^{\mathrm{FB}}$ & $\begin{array}{l}\text { partition coefficient for FB between sun- } \\
\text { flower oil and air, dimensionless }\end{array}$ \\
\hline$t$ & time, s \\
\hline$T$ & absorber temperature, ${ }^{\circ} \mathrm{C}$ \\
\hline TOD $_{\text {DCE }}$ & total organic discharged as DCE, $\mathrm{mg} \mathrm{L}^{-1}$ \\
\hline $\mathrm{TOD}_{\mathrm{FB}}$ & total organic discharged as $\mathrm{FB}, \mathrm{mg} \mathrm{L}^{-1}$ \\
\hline$V_{\text {oil }}$ & volume of sunflower oil, L \\
\hline
\end{tabular}

\section{Acknowledgements}

Support from BIOSAP (CEC Contract No-HPRTN-CT2002-00213), FCT Portugal (Contract No BD/17965/2004), UK BBSRC (Grant No 28/E17405t), Glaxo Smith Kline (GSK), Rohm and Haas (RH) and Membrane Extraction Technology is gratefully acknowledged. Also, we would like to thank Prof. Dick Janssen who kindly provided the DCE degrading microbial culture for this study.

\section{References}

Abumaizar, R.J., Kocher, W., Smith, E.H., 1998. Biofiltration of BTEX contaminated air streams using compost-activated carbon filter media. Journal of Hazardous Materials 60 (2), 111-126.

Amsden, B.G., Bochanysz, J., Daugulis, A.J., 2003. Degradation of xenobiotics in a partitioning bioreactor in which the partitioning phase is a polymer. Biotechnology and Bioengineering 84 (4), 399-405.

Ashelford, K.E., Weightman, A.J., Fry, J.C., 2002. PRIMROSE: a computer program for generating and estimating the phylogenetic range of $16 \mathrm{~S}$ rRNA oligonucleotide probes and primers in conjunction with the RDP-II database. Nucleic Acids Research 30 (15), 3481-3489.

Bastos, F.S.C., Castro, P.M.L., Ferreira Jorge, R.M., 2003. Biological treatment of a contaminated gaseous emission from a paint and varnish plant-from laboratory studies to pilot-scale operation. Journal of Chemical Technology and Biotechnology 78 (11), 1201-1207.

Cai, Z., Kim, D., Sorial, G.A., Saikaly, P., Zein, M.M., Oerther, D.B., 2006. Performance and microbial diversity of a trickle-bed air biofilter under interchanging contaminants. Engineering in Life Sciences 6 (1), $37-42$.

Carvalho, M.F., Ferreira Jorge, R., Pacheco, C.C., De Marco, P., Henriques, I.S., Correia, A., Castro, P.M.L., 2006a. Long-term performance and microbial dynamics of an up-flow fixed bed reactor established for the biodegradation of fluorobenzene. Applied Microbiology and Biotechnology 71 (4), 555-562.

Carvalho, M.F., Ferreira, M.I.M., Moreira, I.S., Castro, P.M.L., Janssen, D.B., 2006b. Degradation of fluorobenzene by Rhizobiales strain F11 via ortho cleavage of 4-fluorocatechol and catechol. Applied and Environmental Microbiology 72 (11), 7413-7417.

Daugulis, A.J., 1997. Partitioning bioreactors. Current Opinion in Biotechnology 8 (2), 169-174.
Daugulis, A.J., Amsden, B.G., Bochanysz, J., Kayssi, A., 2003. Delivery of benzene to Alcaligenes xylosoxidans by solid polymers in a two-phase partitioning bioreactor. Biotechnology Letters 25 (14), 1203-1207.

Emanuelsson, E.A.C., Baptista, I.I.R., Mantalaris, A., Livingston, A.G., 2005. Strain stability in biological systems treating recalcitrant organic compounds. Biotechnology and Bioengineering 92 (7), 843-849.

Ferreira Jorge, R.M., Livingston, A.G., 2000a. Microbial dynamics in a continuous stirred tank bioreactor exposed to an alternating sequence of organic compounds. Biotechnology Bioengineering 69 (4), 409-417.

Ferreira Jorge, R.M., Livingston, A.G., 2000b. Microbial dynamics in an extractive membrane bioreactor exposed to an alternating sequence of organic compounds. Biotechnology and Bioengineering 70 (3), 313-322.

Goodall, J.L., Peretti, S.W., 1998. Dynamic modelling of meta- and para-nitrobenzoate metabolism by a mixed co-immobilized culture of Comamonas spp. JS46 and JS47. Biotechnology and Bioengineering 59 (4), 507-516.

Goodall, J.L., Thomas, S.M., Spain, J.C., Peretti, S.W., 1998. Operation of mixed-culture immobilized cell reactors for the metabolism of meta- and para-nitrobenzoate by Comamonas sp. JS46 and Comamonas sp. JS47. Biotechnology and Bioengineering 59 (1), 21-27.

Johnson, J., Parker, W., Kennedy, K., 2000. Enhanced scrubbing of chlorinated compounds from air streams. Environmental Progress 19 (3), 157-166.

Kim, D., Cai, Z., Sorial, G.A., 2005. Impact of interchanging VOCs on the performance of trickle bed air biofilter. Chemical Engineering Journal 113 (2-3), 153-160.

Koutinas, M., Peeva, L.G., Livingston, A.G., 2005. An attempt to compare the performance of bioscrubbers and biotrickling filters for degradation of ethyl acetate in gas streams. Journal of Chemical Technology and Biotechnology 80 (11), 1252-1260.

Koutinas, M., Martin, J., Peeva, L.G., Mantalaris, A., Livingston, A.G., 2006. An oil-absorber-bioscrubber system to stabilise biotreatment of pollutants present in waste gas. Fluctuating loads of 1,2-dichloroethane. Environmental Science and Technology 40 (2), 595-602.

Koutinas, M., Baptista, I.I.R., Peeva, L.G., Ferreira Jorge, R.M., Livingston, A.G., 2007. The use of an oil absorber as a strategy to overcome starvation periods in degrading 1,2-dichloroethane in waste gas. Biotechnology and Bioengineering 96 (4), 673-686.

Nielsen, D.R., Daugulis, A.J., McLellan, P.J., 2005. Transient performance of a two-phase partitioning bioscrubber treating a benzene-contaminated gas stream. Environmental Science and Technology 39 (22), 8971-8977.

Oliveira, T.A.C., Livingston, A.G., 2003. Bioscrubbing of waste gas-substrate absorber to avoid instability induced by inhibition kinetics. Biotechnology and Bioengineering 84 (5), 552-563.

Poulsen, L.K., Ballard, G., Stahl, D., 1993. Use of rRNA fluorescence in situ hybridisation for measuring the activity of single cells in young and established biofilms. Applied and Environmental Microbiology 59 (5), 1354-1360.

Weber, F.J., Hartmans, S., 1995. Use of activated carbon as a buffer in biofiltration of waste gases with fluctuating concentrations of toluene. Applied Microbiology and Biotechnology 43 (2), 365-369.

Williams, S.C., Hong, Y., Danavall, D.C.A., Howard-Jones, M.H., Gibson, D., Frischer, M.E., Verity, P.G., 1998. Distinguishing between living and nonliving bacteria: evaluation of the vital stain propidium iodide and its combined use with molecular probes in aquatic samples. Journal of Microbiological Methods 32 (3), 225-236. 